\title{
Gastritis and Carditis
}

David A. Owen, M.B.

University of British Columbia, Vancouver, British Columbia, Canada

Dyspepsia is a common clinical problem. Its causes include peptic ulcer disease, gastroesophageal reflux, and functional (nonulcer) dyspepsia. A detailed clinical description of pain does not reliably differentiate the cause. Approximately $\mathbf{8 0 \%}$ of gastroscopies are performed for the investigation of dyspepsia. "Gastritis" is diagnosed endoscopically in $\mathbf{5 9 \%}$ of all stomachs, although in only $3 \%$ are the changes severe. Pathologic examination of unselected gastric biopsy specimens reveals that abnormalities are present in $62-73 \%$, but there is only a weak correlation between endoscopic and histologic findings. For these reasons, it is recommended that endoscopic examination should always be accompanied by biopsy. Ideally, biopsies should be taken in a systematic fashion to include sampling of antrum and corpus. Recent evidence suggests that gastric infection by Helicobacter pylori initially presents as a superficial gastritis. Later it may become atrophic with development of intestinal metaplasia. The onset of atrophic changes may be related to the duration of infection, the strain of the infecting organism, associated dietary factors, or as-yet undefined host factors related to immunity. Persistent superficial gastritis predisposes to duodenal ulcer and gastric mucosa-associated lymphoid tissue lymphoma. Atrophic gastritis predisposes to gastric ulcer and adenocarcinoma. Evidence is accumulating that in some patients, pernicious anemia may be an end result of $\boldsymbol{H}$. pylori-induced atrophic gastritis. Reactive gastropathy is a relatively common finding in gastric biopsies; in most instances it is associated with either reflux of duodenal contents or therapy with nonsteroidal anti-inflammatory drugs. Lymphocytic gastritis, eosinophilic gastritis, and the gastritis associated with Crohn's disease are distinct morphologic entities. Lymphocytic gastritis and eosinophilic gastritis have a variety of clinical associ-

Copyright (C) 2003 by The United States and Canadian Academy of Pathology, Inc.

VOL. 16, NO. 4, P. 325, 2003 Printed in the U.S.A.

Date of acceptance: January 8, 2003.

Address reprint requests to: David A. Owen, M.B., Dept. of Pathology and Laboratory Medicine, Vancouver General Hospital, 855 West 12th Avenue, Vancouver, B.C. Canada V5Z 1M9; fax: (604) 875-4797; e-mail: dowen@vanhosp.bc.ca.

DOI: 10.1097/01.MP.0000062995.72390.14 ations. Carditis is a controversial topic: currently opinions are divided as to whether it is the result of gastroesophageal reflux or a proximal extension of $H$. pylori infection from the remainder of the stomach.

KEY WORDS: Atrophic gastritis, Carditis, Gastric cardia, Gastric Crohn's disease, Gastritis, Helicobacter, Lymphocytic gastritis, Pernicious anemia, Proton pump inhibitors, Reactive gastropathy.

Mod Pathol 2003;16(4):325-341

Most gastroscopies are performed for the investigation of dyspepsia (1-7). This is a common clinical problem but is rarely life-threatening. The causes of dyspepsia include peptic ulcer disease $(30 \%)$, gastroesophageal reflux (29\%), and nonulcer (functional) dyspepsia (40\%). The cause of functional dyspepsia is unclear at the present time, although in many instances it may be related to abnormalities of gut motility. In $<1 \%$ of cases is gastric cancer a cause of dyspepsia. A detailed description of the symptoms of dyspepsia does not reliably differentiate the cause, although the presence of heartburn strongly suggests a component of gastroesophageal reflux.

Correlations among patient symptoms, endoscopic appearances, and biopsy findings of gastritis are imperfect (4-6). Agreement is best in cases where peptic ulcer or another focal lesion is identified. A study by Khakoo et al. (7) from the United Kingdom illustrates the problems encountered. Endoscopic and histologic findings were reviewed in 167 patients who underwent gastroscopy for dyspeptic symptoms. Of these, 98 patients $(57 \%)$ had endoscopic evidence of gastritis. In $42 \%$ of patients, gastritis involved the antrum alone, in $7 \%$ it involved the corpus alone, and in $51 \%$ there was a pangastritis present. Endoscopically the gastritis was thought to be mild in $66 \%$, moderately severe in $30 \%$, and severe in $4 \%$. When these endoscopic assessments were compared with the results of histology, it was found that 26 patients (27\%) with endoscopic gastritis had normal histology. A perfect endoscopic-histologic correlation was obtained in only 12 patients, all of whom had "raised erosive 
gastritis." Forty-three patients had normal endoscopic findings; however, only 17 (38\%) had normal histology. In the remaining 26 patients (62\%), there was histologic evidence of gastritis. Other studies $(4,5)$ have confirmed these observations and demonstrated that endoscopic findings of mucosal abnormalities such as erythema, edema, and friability may be accompanied by normal histologic findings. Even endoscopically visualized erosions may also consist of mucosa that is normal histologically. The reasons underlying this discrepancy are unclear, especially in view of the reasonable endoscopichistologic correlation noted in large bowel biopsies. These studies do, however, imply that it is perfectly reasonable for a pathology diagnosis to contradict an endoscopic impression, even one that is rendered by a skilled and experienced gastroenterologist.

Studies have been performed investigating the association of dyspepsia with the presence of active gastritis and Helicobacter pylori organisms (1-3). Typical results are presented in a multinational study from Talley and Hunt (1). This group studied 278 patients infected with $H$. pylori who also had dyspepsia. One hundred thirty-five patients were treated with antibiotics, and 143 patients served as controls. At the commencement of the study, there was no association identified between the severity of symptoms and the histologic grade of gastritis. At the end of 1 year, symptom relief was identical in both groups ( $22 \%$ versus $23 \%$ ). This and similar studies suggest that uncomplicated $H$. pylori infection is not a significant cause of dyspepsia.

Some investigators have suggested that gastric biopsy need not be performed routinely during gastroscopy. This opinion has been authoritatively rejected by Carpenter and Talley (8), who have pointed out that biopsy should be an integral part of endoscopic examination because the current data suggest that gross visualization alone cannot reliably detect gastric mucosal disease. Only histologic examination can provide an accurate diagnosis of gastritis. Furthermore, the term gastritis should not be used indiscriminately to describe conditions with and without histologic evidence of inflammation. These authors recommend a standard approach to biopsying the stomach.

\section{THE SYDNEY SYSTEM}

The Sydney system (9) and its modifications are the most widely used method for the standardized reporting of gastric biopsies. The Sydney system requires that five locations in the stomach should be sampled histologically: the greater and lesser curvature in the antrum, the greater and lesser curvature in the corpus, and the incisura. This scheme is ideal for academic and comparative purposes but is complicated and time-consuming. In routine practice, it is usually satisfactory for one to three fragments of gastric mucosa to be taken from both antrum and corpus and submitted to the laboratory in separate containers.

Histologic examination of biopsies using the Sydney system requires that some variables $(H$. pylori density, neutrophil infiltration, mononuclear infiltration, atrophy, and intestinal metaplasia) are graded on a $0-4+$ scale. A recent publication (9) provides a series of cartoons illustrating the scoring and providing a ready visual comparison scale. Although this grading system may be valuable for scientific studies, it appears at the present time that it conveys little significant clinical or prognostic information. Ungraded variables in the Sydney system include surface epithelial damage, lymphoid follicles, foveolar hyperplasia, pseudopyloric metaplasia, pancreatic acinar metaplasia, and endocrine cell hyperplasia. These are assessed simply as to whether they are absent or present. In addition to these listed variables, some clinical situations will suggest examination of biopsies for granulomas, eosinophils, apoptosis, viral inclusions, epithelial lymphocytosis, and abnormal contour of foveolae.

A simpler system for the histologic reporting of gastritis is to derive a checklist that includes the factors listed in Table 1. If these histologic features are assessed in each biopsy set, they will provide a morphologic description that will enable a diagnosis to be derived. A low-power microscopic assessment should be performed first to determine the location of the disease process and whether it is antral predominant, corpus predominant, or a pangastritis. Next, assessment should be made as to whether the disease is diffuse or focal and whether it affects only the superficial portion of the mucosa or is a full-thickness involvement. Atrophy and metaplasia should be assessed as to whether they are present or absent. The type of inflammation may be active or chronic or contain elements of both. The presence or absence of $H$. pylori organisms should be evaluated. Last, any additional findings (for example, granuloma or viral cytopathic changes) should be tabulated.

TABLE 1. Morphologic Determinants of Gastritis

\begin{tabular}{ll} 
Location & $\begin{array}{c}\text { Antral predominant, corpus predominant, } \\
\text { or pangastritis } \\
\text { Focal or diffuse }\end{array}$ \\
Focality & Superficial or full thickness \\
Atrophy & Present or absent \\
Metaplasia & Present or absent \\
Inflammation & Active, chronic, or both \\
Organisms & H. pylori present or absent \\
\hline
\end{tabular}




\section{CLASSIFICATION OF GASTRITIS}

There is no entirely satisfactory and universally agreed-on classification of gastritis. The scheme proposed in Table 2 is similar to the recommendations of Appelman (6) and Whitehead (10). It is organized along traditional lines with active and chronic categories and includes specific forms of chronic gastritis characterized, for example, by eosinophil infiltration or granuloma formation. Some of the entities listed are loosely defined and overlap with other entities. This is inevitable as the classification includes some conditions defined by morphology and some by etiology. The classification represents the best compromise that can be obtained at the present time, although it will doubtless change in the future. The formerly used alphabetic nomenclature $(\mathrm{A}, \mathrm{B}, \mathrm{AB}$, and $\mathrm{C})$ has been dropped because it was felt to be confusing and to add nothing to our understanding of disease processes or patterns.

\section{HELICOBACTER PYLORI GASTRITIS}

The vast majority of patients diagnosed with $H$. pylori gastritis have a chronic gastritis that has been present for many years. In most instances, there is no history of any previous episode that may be identified as an acute gastritis. However, in a small minority of patients, the onset of $H$. pylori infection is characterized by an episode of abdominal pain with vomiting and transient gastric hypochlorhydria. Gastric biopsies taken at this time will show epithelial infiltration by neutrophils without any chronic inflammatory component. Evidence suggests that in $20 \%$ of cases, acute $H$. pylori gastritis is self-limiting. The remainder of patients go on to develop chronic gastritis. The classic histologic appearances of chronic $H$. pylori gastritis are well known. The inflammation is antral predominant, although changes may also be encountered in the corpus and cardiac mucosae. At least initially, the inflammation is superficial (Fig. 1) and is confined

\section{TABLE 2. Classification of Gastritis}

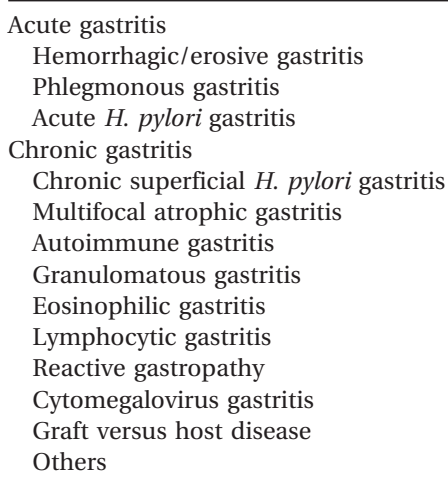

to the portion of mucosa occupied by foveolae. The superficial lamina propria contains a rich infiltrate of chronic inflammatory cells, including lymphocytes and plasma cells. Neutrophils are present and commonly migrate into the foveolar epithelium (Fig. 2). The intensity of neutrophil infiltration is considered proportionate to the degree of activity of the gastritis. With heavy infections, the superficial epithelium may have a ragged appearance with cytoplasmic mucin loss (micropapillary tufting). Lymphoid follicles with germinal center formation are exceedingly common (Fig. 3), and these are present in the lower portion of the mucosa, frequently straddling the muscularis mucosae. Organisms may be detected within the mucous layer covering the surface epithelium and within foveolae. When organisms are abundant, they are usually readily detected on routine hematoxylin and eosin sections. However, the presence of scanty organisms may require special stains for their demonstration (2). A wide variety of special stains are available for this purpose (Fig. 4). These include silver stains, methylene blue combinations, and Giemsa stains. They are all of similar specificity and sensitivity so that the choice of stain remains a matter of individual preference. Immunohistochemical stains for Helicobacter organisms are also available. They are more specific but probably not more sensitive than the usual special stains and at the present time are not used widely on a routine basis.

\section{MULTIFOCAL ATROPHIC GASTRITIS}

There is little doubt that in most stomachs, multifocal atrophic gastritis (MAG) develops secondary to long-standing $H$. pylori infection (11-14). In rare instances it may be secondary to other conditions such as granulomatous gastritis, inflammatory bowel disease, or radiation gastritis. As atrophic gastritis develops from $H$. pylori gastritis, the inflammation becomes more extensive and spreads to involve the full thickness of the mucosa (Fig. 5). Initially, glands are compressed and separated by the inflammatory infiltrate, but ultimately, they are destroyed. This destruction occurs in a patchy fashion. When atrophy occurs, the lamina propria will become fibrotic, and the epithelium will undergo intestinal metaplasia (13). At this stage, the gastric acid output may fall, and Helicobacter organisms may become less frequent or even undetectable. These changes not uncommonly result in resolution of active inflammation and restoration of normal or near-normal mucosal architecture in the patches of mucosa that have not undergone atrophy.

Considerable discussion is present in the pathology literature that attempts to precisely define and 


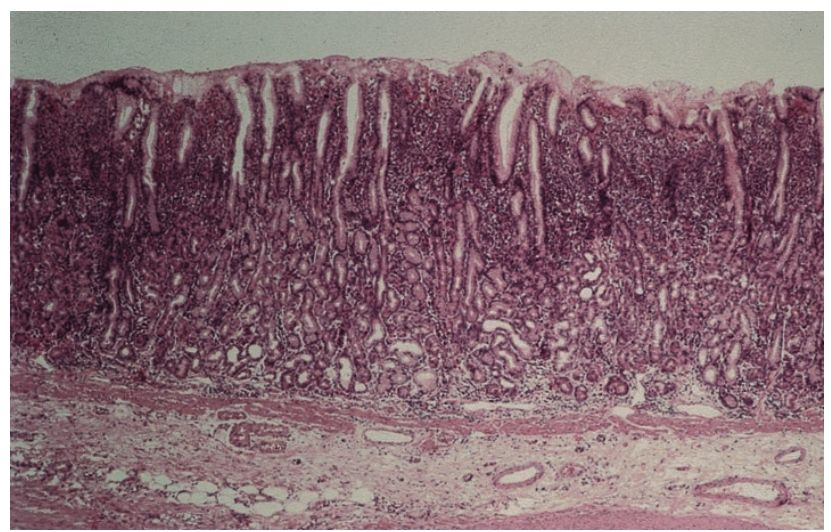

FIGURE 1. Superficial H. pylori gastritis. Inflammation is confined to the portion of mucosa occupied by the foveolae.

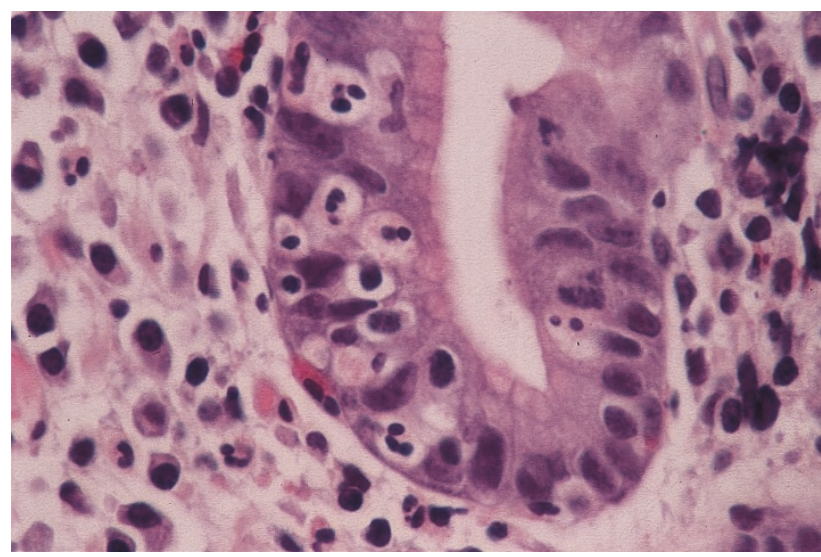

FIGURE 2. Neutrophils infiltrating foveolar epithelium in a case of active $H$. pylori gastritis.

quantify atrophy $(9,13,15)$. This distinction between atrophy and nonatrophy has considerable theoretical importance because of the recognition that atrophy is the first step in an atrophymetaplasia-dysplasia-carcinoma sequence $(16,17)$. If, for example, certain drugs (e.g., proton pump inhibitors), taken over many years were to promote the development of gastric atrophy in the presence of $H$. pylori infection (18), it is conceivable that they could be considered carcinogenic. It is important to emphasize that at the present time, a link between proton pump inhibitors and gastric cancer has not been established. Nevertheless, many gastroenterologists will seek to detect and treat $H$. pylori infection before placing patients on long-term proton pump inhibitors for the treatment of gastroesophageal reflux.

It has been recommended that the term atrophic gastritis be restricted to instances in which either intestinal metaplasia is present (Fig. 6) or there is a morphologically identifiable loss of glands and replacement within the lamina propria by extracellular matrix and fibroblasts (13). This rigid definition of atrophy will exclude cases in which there is fullthickness mucosal inflammation and simple sepa-

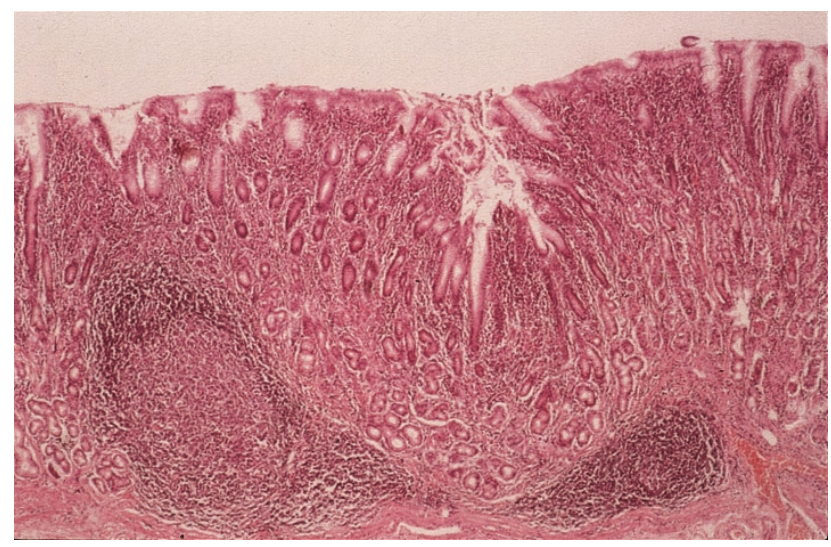

FIGURE 3. Lymphoid follicles with germinal center formation in an example of $H$. pylori gastritis.

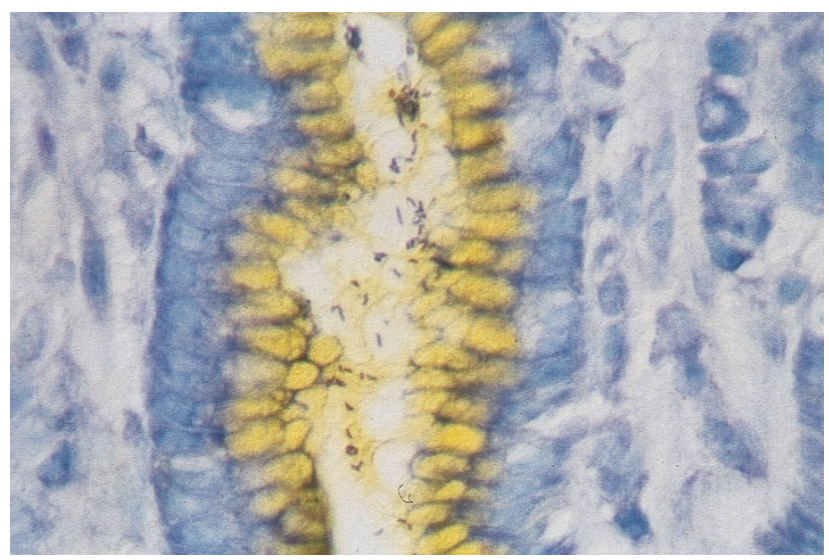

FIGURE 4. H. pylori organisms are readily identified at medium power microscopic examination (Leung stain).

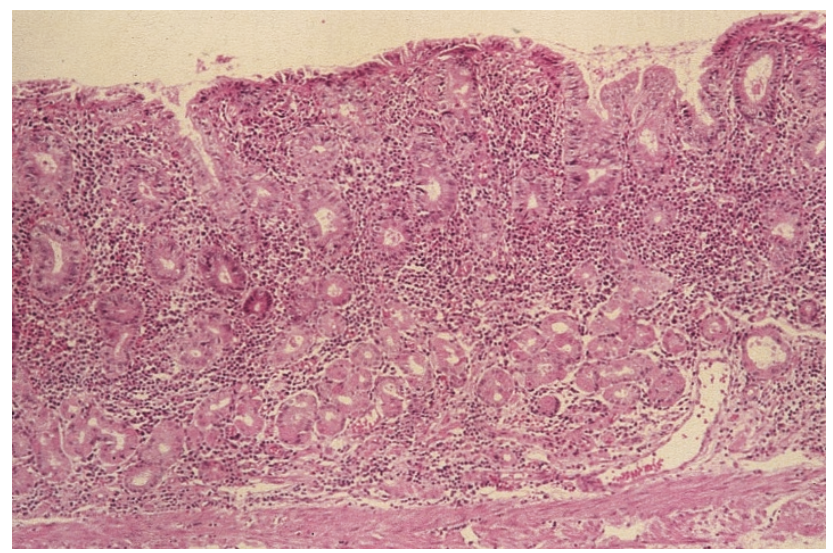

FIGURE 5. Advanced H. pylori gastritis with full-thickness mucosal inflammation.

ration of glands by inflammatory infiltrate (Fig. 7). Early cases of atrophy may, therefore, require confirmation by trichrome stains to demonstrate fibrosis or reticulin stains to demonstrate architectural collapse (Fig. 8). Obviously, in an individual case, the presence of early atrophy may be a subtle finding unlikely to be of clinical significance. However, this distinction is of more importance if the patient 


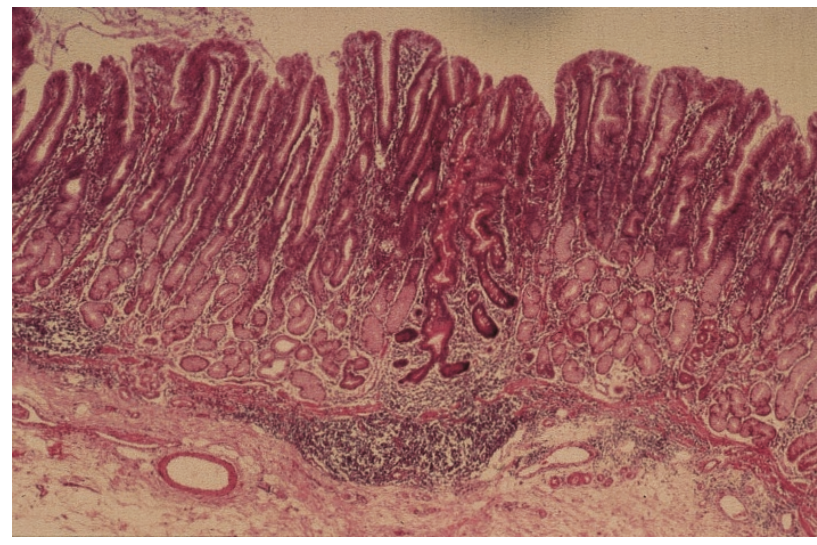

FIGURE 6. Focus of intestinal metaplasia in an example of multifocal atrophic gastritis. Note that the adjacent mucosa shows superficial gastritis.

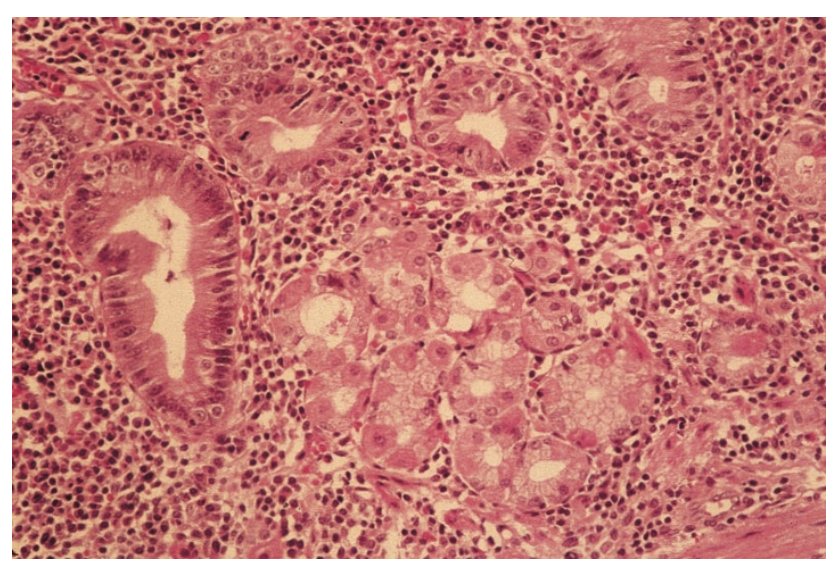

FIGURE 7. In this example of advanced H. pylori gastritis, it is unclear whether true atrophy is present or whether the glands are simply separated by an extensive inflammatory infiltrate.

forms part of a scientific study tracking the development of atrophy in certain clinical conditions. The literature on atrophic gastritis should, therefore, be read critically with respect to the exact pathologic definition of atrophy. Reports of worsening atrophic gastritis after Omeprazole therapy (18) or cures of atrophic gastritis after antiHelicobacter therapy (19) may imply a diagnosis of atrophy that is less rigid than the one suggested above (20). Furthermore, claims on the basis of biopsies that a focal disease of the stomach has undergone reduction in extent and severity are difficult to accept unless a study has examined multiple biopsies from large numbers of patients.

Why some patients with $H$. pylori infection develop atrophy whereas the remainder do not progress beyond superficial gastritis is unknown (13) (Table 3). In superficial gastritis, organisms are in direct contact with surface foveolar epithelial cells. Direct cell damage may be caused by release of cytotoxins such as ammonia or phospholipases. It may also be caused indirectly, via bacterial stimulation of tumor necrosis factor (TNF), interferons,
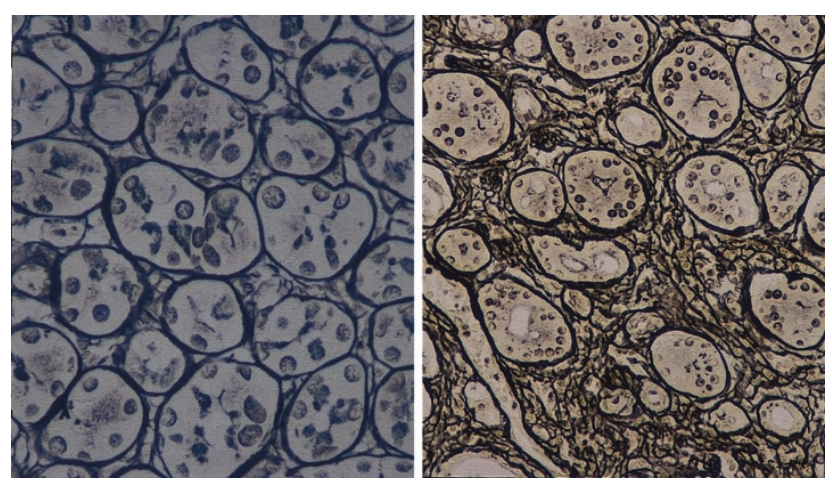

FIGURE 8. The reticulin patterns in normal gastric mucosa (A) and atrophic gastritis $(\mathbf{B})$.

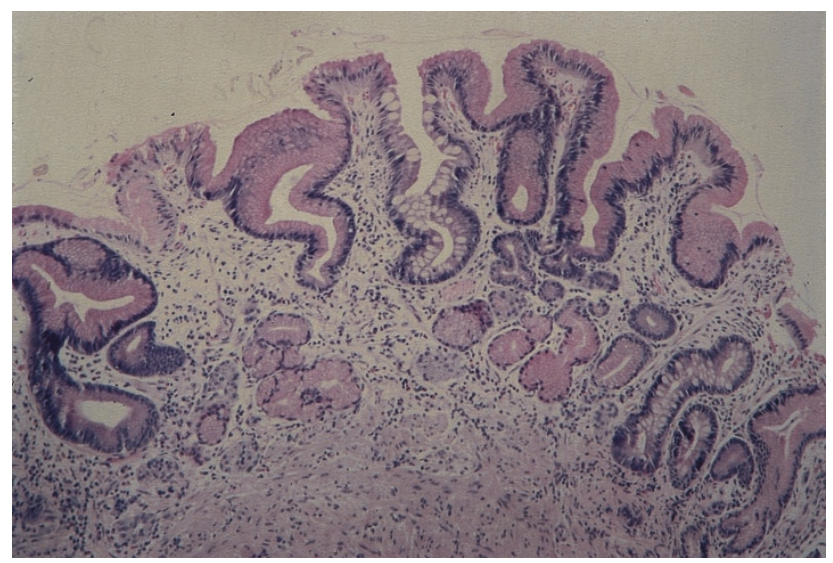

FIGURE 9. Advanced gastric atrophy with "burned-out" inflammation from a case of pernicious anemia.

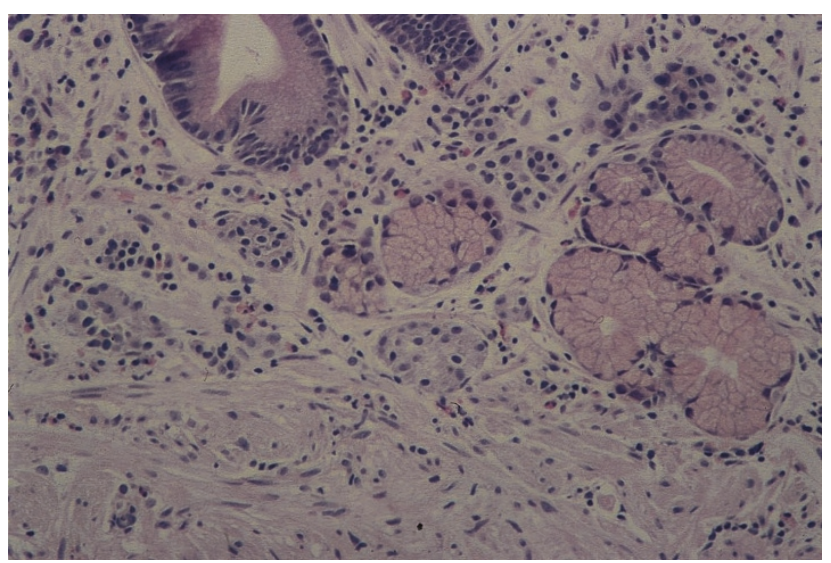

FIGURE 10. Pernicious anemia: nodular hyperplasia of gastric ECL cells.

and interleukins $(13,21)$. However, bacteria are not directly in contact with gastric glands, suggesting that full-thickness mucosal inflammation is a secondary response to a complex host reaction that involves an active inflammatory response, T- and B-cell activation, and autoimmunity (22). Factors that may promote the inflammatory progression and development of mucosal atrophy include differences in the strain of infecting bacteria (especial- 
TABLE 3. Progression of Helicobacter pylori gastritis

TABLE 3

Progression of Helicobacter pylori gastritis

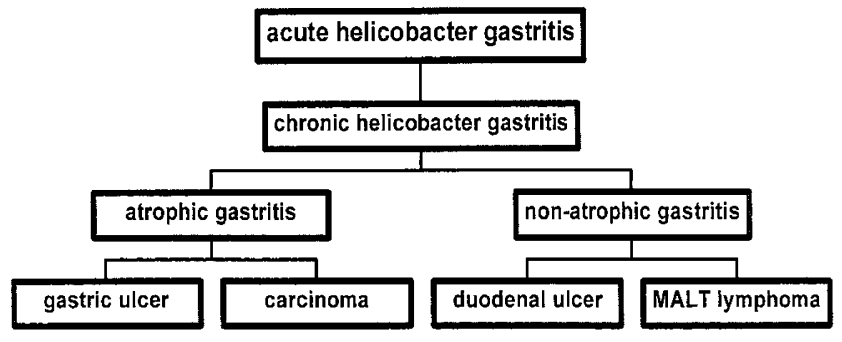

ly those with cagA; 23-25); age at which infection is first acquired; duration of infection; and host factors that control the development of autoimmunity $(22,23)$.

It is controversial as to how many patients with superficial $H$. pylori gastritis will ultimately develop MAG and how long these changes take to develop. Studies from the Netherlands have suggested that in $H$. pylori-infected subjects, atrophic gastritis increases by $1-3 \%$ per year (12). In a cohort study in Scandinavia, Valle et al. (26) studied 102 patients who were followed up for 32 years. At initial examination, 66 patients had superficial gastritis. Thirtytwo years later, $44(67 \%)$ still had superficial gastritis, $20(30 \%)$ had developed atrophic gastritis, and 8 (12\%) had normal gastric mucosa. At the present time it is not possible to predict which patients with superficial gastritis will ultimately develop MAG.

\section{AUTOIMMUNE GASTRITIS}

Patients with pernicious anemia typically have advanced gastric mucosal atrophy, with extensive intestinal metaplasia mainly affecting the corpus mucosa (Fig. 9). Inflammation is usually sparse, and H. pylori organisms are rarely seen. Small numbers of parietal cells may still be present, and it is important to realize that their presence does not invalidate a diagnosis of pernicious anemia or autoimmune gastritis. The antral mucosa may be normal, inflamed, or show focal atrophy. However, in most instances, the antral mucosa is not entirely normal when it has been thoroughly sampled. In some individuals, corpus gland atrophy is accompanied by proximal expansion of antral mucussecreting glands (so-called mucous gland metaplasia). Linear hyperplasia of antral gastrin-secreting cells ( $\mathrm{G}$ cells) is commonly encountered. Hyperplasia of endocrine cells in the gastric corpus is also a common feature. These are histamine-secreting enterochromaffin-like cells (ECL), and the hyperplasia is typically nodular (Fig. 10). Extreme degrees of hyperplasia may ultimately result in the formation of multifocal carcinoid tumors $(27,28)$.

The type of gastritis associated with pernicious anemia (corpus predominant with extensive atrophy and intestinal metaplasia) has been termed autoimmune gastritis. It may be found in patients with established pernicious anemia and in persons who may later develop pernicious anemia when the several years' supply of vitamin B12 that is stored in the liver becomes exhausted (29). For many years, it was assumed that autoimmune gastritis was a separate entity with no relationship to antral predominant gastritis or to $H$. pylori. The supposed trigger for mucosal damage was either serum autoantibodies to intrinsic factor and parietal cells (directed against the $\mathrm{H}+/ \mathrm{K}+$ ATPase on the secretory canaliculi) or cytotoxic CD4 T-lymphocytes that, when activated, express CD25 (29).

A number of recent articles, however, have suggested a possible causal link between $H$. pylori and autoimmune gastritis. It is well established that $H$. pylori patients with diffuse antral gastritis have gastric hyperacidity and are at risk of developing duodenal ulcers (22). Conversely, H. pylori patients with MAG have hypoacidity and are at risk of developing gastric ulcers. In addition, however, $\leq 80 \%$ of patients with $H$. pylori may have autoantibodies directed against the canalicular membranes of parietal cells or the luminal membrane of foveolar epithelium (30-33). Moreover, the canalicular antibody has $\mathrm{H}+/ \mathrm{K}+$ ATPase specificity (34). This process is one of antigenic mimicry (35). Circulating antibodies or lamina propria $\mathrm{T}$ cells may be the trigger for parietal cell destruction.

Further evidence of a direct causal relationship between $H$. pylori and pernicious anemia is provided by reports of amelioration of anemia and elevation of serum vitamin B12 levels after antibiotic treatment of infected anemic patients (36). Epidemiologic evidence in support of the association comes from a study of first-degree relatives of patients with pernicious anemia and patients with duodenal ulcer (37). Not surprisingly, the relatives of patients with pernicious anemia had a higher prevalence of MAG than did the relatives of ulcer patients. However, the prevalence of $H$. pylori in both groups was identical, except in the geriatric age group, in which the prevalence of organisms declined in the pernicious anemia group. Despite this decline, the severity of MAG increased in the pernicious anemia group.

When all of this information is collated, it seems probable that $H$. pylori infection does play a role in initiating and promoting MAG, which in some genetically susceptible individuals can lead to extensive corpus mucosal atrophy with subsequent development of pernicious anemia. This does not 
imply, however, that all cases of pernicious anemia develop via this mechanism.

\section{THE STOMACH AFTER $\boldsymbol{H}$. PYLORI ERADICATION}

Various investigators have studied stomachs after $H$. pylori eradication (38-43). Some differences exist in the results obtained, probably because of the variability in the way that atrophy was diagnosed and because of the difficulties of properly sampling the gastric mucosa by multiple biopsies.

Organisms disappear rapidly after the institution of antibiotic therapy and may be undetectable after 1 week of treatment. As the organisms are disappearing, they may lose the usual gull-wing appearance and assume a coccoid form. At this stage, the organisms may be morphologically unrecognizable by standard special stains and can only be detected by immunohistochemical methods. Neutrophils within the mucosa also disappear quickly and are eliminated $6-8$ weeks after treatment $(38,40)$. After this period, a finding of gastric mucosal neutrophils usually indicates treatment failure (41). Chronic inflammation is much slower to disappear. The corpus mucosa is usually normal 1 year after treatment (40), but the antral mucosa may be diffusely abnormal for $\leq 2$ years. After 4 years, the antral mucosa does revert to nearly normal, although degenerate lymphoid aggregates may persist (38). Some investigators report that intestinal metaplasia remains unchanged $(38,42,43)$, whereas others report a reduction in extent and severity $(39,41)$.

\section{PROTON PUMP INHIBITORS}

Long-term treatment with proton pump inhibitors (PPIs) is commonly used for patients with gastroesophageal reflux disease (GERD). These patients may or may not have associated $H$. pylori gastritis. PPIs do not produce gastritis in Helicobacter-negative patients. In H. pylori-positive patients who are taking PPIs, some studies report an increase in corpus gastritis, with a lessening of antral gastritis $(44,45)$. However, organisms are still detected at all locations. Additional studies report an increase in the incidence of atrophy $(4.7 \%$ annually versus $1-3 \%$ for patients not taking PPIs versus $0.7 \%$ for noninfected patients; 44-46). Other studies have not confirmed these findings (47). It is tempting to ascribe these differences to varying histologic criteria for the diagnosis of atrophy (13). At the present time, it is unproven whether any increase in atrophy might predispose to the development of carcinoma of the stomach.

Patients on long-term PPIs may develop G-cell and ECL hyperplasia as a consequence of druginduced achlorhydria. Hyperplasia may be diffuse linear or micronodular (46). Micronodular hyperplasia is most likely to occur in individuals who are $H$. pylori positive. Linear hyperplasia is equally prevalent in $H$. pylori-positive and -negative individuals. Carcinoid tumors do not appear to occur more frequently among individuals on long-term PPI therapy.

Within a few weeks of commencing PPI therapy, patients develop characteristic morphologic changes in corpus glands. These consist of dilatation with swelling and bulging of the superficial cytoplasm of the parietal cells (so-called parietal cell protrusion; Fig. 11). The glands become lined by cells with a serrated rather than a smooth border $(48-50)$. There is evidence that this protrusion is secondary to hypergastrinemia $(51,52)$. It does not, however, appear to be related to $H$. pylori infection (51).

Long-term PPI therapy has also been associated with the development of fundic gland polyps. Typically these are sessile, multiple, and measure $<1.0$ $\mathrm{cm}$ in diameter (49). They are present in $17 \%$ of patients after 3 months' treatment with PPIs and in $35 \%$ of patients after 5 months' treatment ( $8 \%$ of untreated patients have polyps; 50). Polyps are more likely to develop in $H$. pylori-negative patients on PPI treatment (50). Anecdotal evidence suggests that the polyps regress when PPI treatment is stopped, although they can reform if treatment is reinstituted (49). Some reports have indicated that the morphology of PPI-induced fundic gland polyps is different from polyps that occur sporadically. PPI-induced polyps characteristically have isolated glandular dilatation and do not demonstrate the foveolar distortion and hyperplasia that may accompany sporadic polyps. Some investigators, however, deny that an association exists between gastric fundic gland polyps and treatment with proton pump inhibitors (53).

\section{HELICOBACTER HEILMANNII GASTRITIS}

This organism was formerly referred to as Gastrospirillum homis. The organism is helical, measuring 3.5-7.5 $\mu \mathrm{m}$ in length and $0.9 \mu \mathrm{m}$ in diameter, with truncated ends flattened at the tips and $\leq 12$ sheathed flagellae, $28 \mathrm{~nm}$ in diameter, at each pole (54; Fig. 12). In populations living in North America and Europe, the prevalence of infection is between 0.3 and $1.1 \%$ of the general population (55-58). In populations living in southeast Asia, the infection rate may be as high as 6\% (59). Most infected persons are symptomatic and complain of dyspepsia, epigastric pain, or acid reflux $(54,56)$; however, asymptomatic cases have also been described (60).

$H$. heilmannii appears to be acquired by human contact with farm animals and household pets (58, 
61). Biopsies from infected patients demonstrate changes that are similar to but less severe than the appearances in $H$. pylori gastritis $(55,57,59)$. Lymphoid aggregates and scanty epithelial neutrophil infiltration are encountered, but micropapillary tufting and intestinal metaplasia do not occur (57). The characteristic spiral organisms are readily identified by the same range of special staining techniques employed for identification of $H$. pylori (59). Some patients benefit symptomatically from antibiotic treatment (56).

\section{REACTIVE GASTROPATHY}

Reactive gastropathy is the second commonest diagnosis made on gastric biopsy material in North America (8). It has also been referred to as reflux gastritis, chemical gastritis, and Type $\mathrm{C}$ gastritis. The condition was originally described in the stomachs of patients who had undergone gastric surgery (62-64). It was found to be most common after Billroth II gastrectomy but was also encountered after vagotomy and pyloroplasty (64). More recently, it has become recognized that reactive gastropathy may be seen in the intact stomach (65). In some instances, the disease appears to be the result of bile reflux through an intact pylorus, in which case it has been linked to persistent abdominal pain after cholecystectomy (66) and to gastroesophageal reflux disease $(67,68)$. In other instances, reactive gastropathy is secondary to drug therapy, particularly with nonsteroidal anti-inflammatory agents (NSAIDs; 68-74). It has been estimated that patients taking long-term NSAIDs on a regular basis have a $50 \%$ incidence of gastric erosions and a $10-30 \%$ incidence of gastric ulcer (72). About $0.75 \%$ of patients taking NSAIDs for $>6$ months develop clinically significant complications (72). There is evidence that drugs selectively inhibiting cyclooxygenase-2 (coxibs) produce significantly

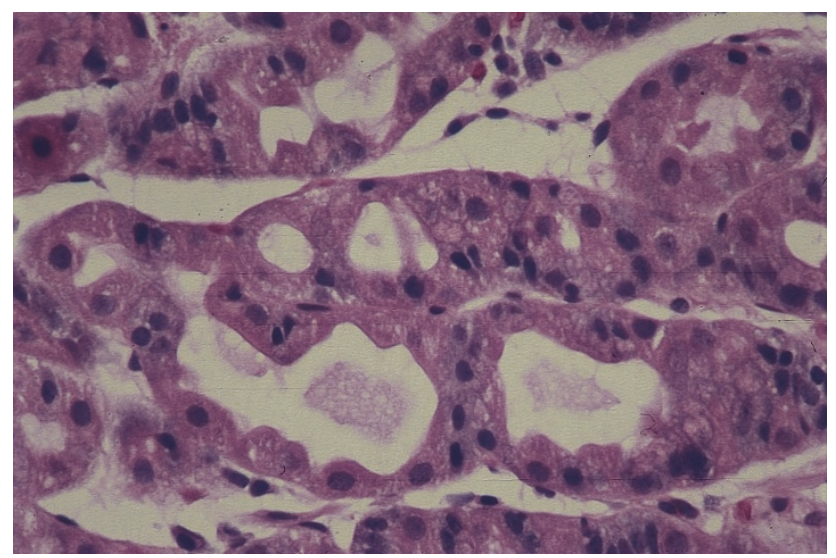

FIGURE 11. Gastric corpus glands after several months' treatment with proton pump inhibitors. The lumen is dilated, and the parietal cells show a serrated surface contour. fewer clinical gastrointestinal complications than nonselective NSAIDs (76). At the present time, however, it is unclear whether coxib therapy results in less severe reactive gastropathy. Interestingly, it appears that NSAIDs are not a risk factor for classical peptic duodenal ulceration $(70,72,73)$. There seems to be some agreement that the risk of gastric mucosal injury with NSAIDs is compounded by $H$. pylori $(68,69)$, although this association has been denied by other investigators (75). Unless complications are present (erosions or ulcers), reactive gastropathy appears to be an asymptomatic lesion (71). The prevalence of reactive gastropathy in patients taking NSAIDs has been estimated to be between 34 and 45\% (69, 70, 75).

The histopathologic features of reflux gastropathy have been well described by Dixon et al. (78). They include foveolar hyperplasia, edema and smooth muscle fibers in the lamina propria, vasodilation and congestion of superficial mucosal capillaries, and a paucity of active and chronic inflammatory cells. These features may each be graded on a $0-3+$ scale to provide a "reflux score" (maximum, $15)$. Scores of $\geq 10$ are regarded as highly characteristic of reactive gastropathy (78). In examples of prominent foveolar hyperplasia, there is often a corkscrew appearance of the superficial mucosa (Fig. 13). Epithelial cells lining the foveolae show loss of cytoplasmic mucus with nuclear enlargement and hyperchromasia (Fig. 14). The abnormal contour of the foveolae and the presence of regenerative cellular changes are considerably easier to assess than mucosal congestion and edema. These features are recommended as being the most useful for the diagnosis of reactive gastropathy. As pointed out by El-Zimaity et al. (77), these histologic features are not present in every stomach from NSAIDs patients, and furthermore, they may be encountered in non-NSAIDs patients, particularly those who have $H$. pylori infection. Nevertheless, it has

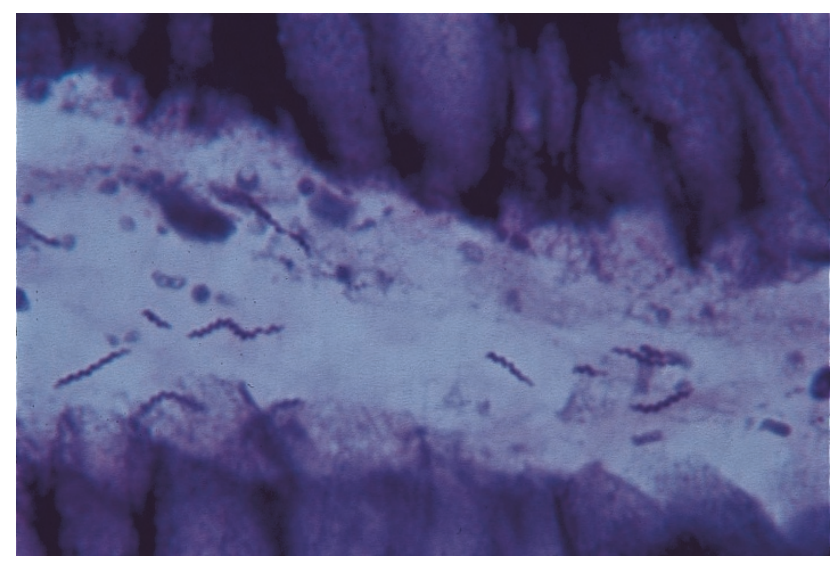

FIGURE 12. The tightly coiled spiral organisms of Helicobacter heilmannii. 


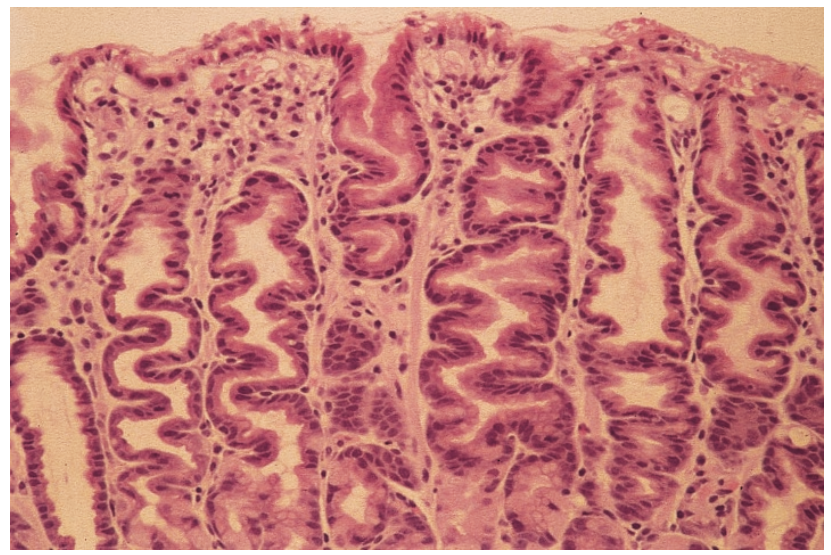

FIGURE 13. Reactive gastropathy demonstrating a corkscrewlike contour of the foveolae.

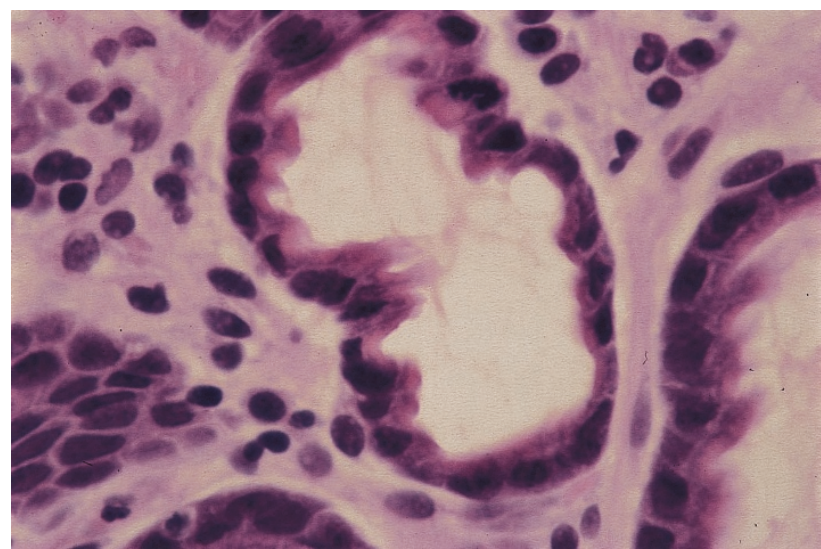

FIGURE 14. Reactive changes in foveolar epithelial cells. Note the absence of inflammatory cells.

been my experience that many patients diagnosed endoscopically as having "severe gastritis" often have reactive gastropathy on biopsy. On theoretical grounds, one would expect gastropathy secondary to reflux to be diffuse and located adjacent to the pylorus, and gastropathy secondary to NSAIDs to be more patchy throughout the antrum. There is good evidence for believing that the gastric mucosal changes are secondary to chemically mediated damage at the mucosal surface, producing increased surface exfoliation and epithelial turnover (78).

\section{LYMPHOCYTIC GASTRITIS}

The gross morphology of lymphocytic gastritis varies according to its severity. In low-grade lymphocytic gastritis, the stomach is endoscopically normal. In more severe disease, there may be scattered chronic erosions (so-called varioliform gastritis; Fig. 15). The most severe form is characterized by enlarged mucosal folds, resembling Menetrier's

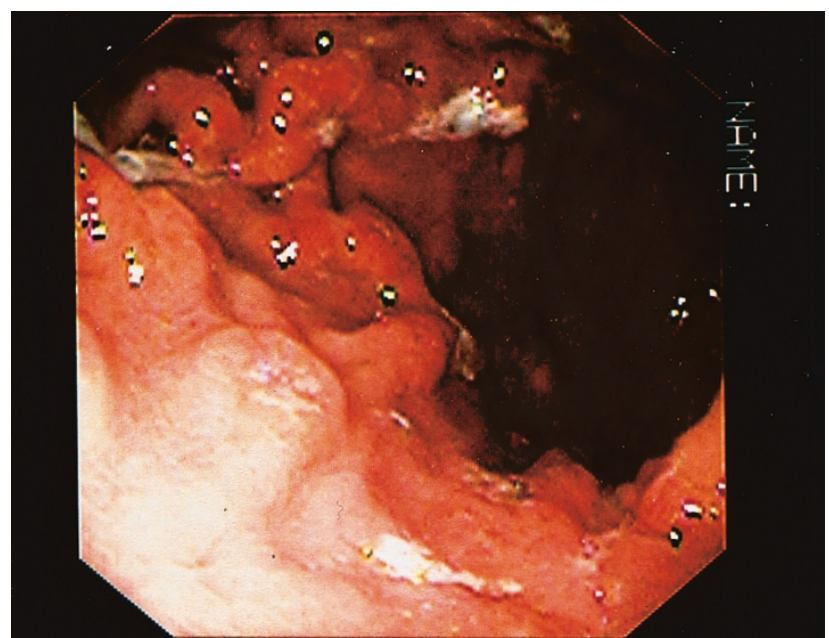

FIGURE 15. Endoscopic appearances of varioliform gastritis.

disease, and is accompanied by anemia and mucosal protein loss $(79-84)$.

Low-grade lymphocytic gastritis is symptomless and is generally discovered by random biopsies of endoscopically unremarkable mucosa. It is an uncommon condition that is present in $0.83 \%$ of unselected gastric biopsies (79) and in $1.7-4.5 \%$ of inflamed gastric biopsies $(85,86)$. The essential diagnostic feature is the presence of increased mucosal lymphocytes in the lamina propria, as well as in the surface and foveolar epithelium. Usually, the number of epithelial lymphocytes is so obviously increased that formal counting of them is not needed (Fig. 16). If counting is necessary, 25 lymphocytes per 100 epithelial cells is considered the minimum for diagnosis. Most cases will, however, have 30-65 lymphocytes per 100 epithelial cells (87). The lymphocytes are small and round with no nuclear atypia (Fig. 17). They may be surrounded by a clear halo that is generally considered to be a fixation and shrinkage artifact. Small lymphoepithelial lesions (collections of up to three lympho-

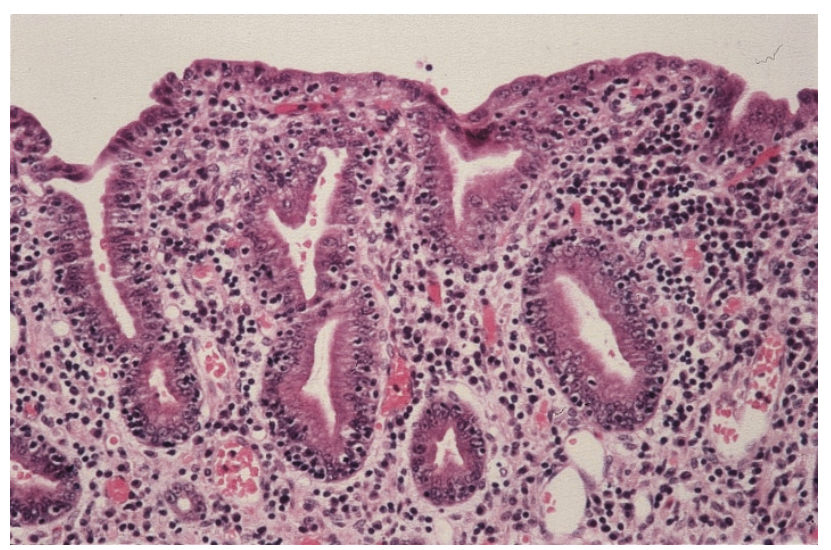

FIGURE 16. Lymphocytic gastritis. The number of intraepithelial lymphocytes is so great that counting is not required to establish the diagnosis. 
cytes) may be present but are rare. The overwhelming majority of intraepithelial lymphocytes are of T-cell origin. Intraepithelial lymphocytes and lymphoepithelial lesions are most numerous in cases in which there is varioliform gastritis or giant folds. The giant folds are the result of foveolar hyperplasia. The results of a study of patients with giant gastric mucosal folds distinguished two separate subgroups: one with hypertrophic lymphocytic gastritis (HLG) and one with massive foveolar hyperplasia (MFH; 84). HLG cases were characterized by severe mucosal inflammation, large numbers of intraepithelial lymphocytes, and mild foveolar hyperplasia. MFH cases were characterized by conspicuous foveolar hyperplasia, significantly thickened mucosa, and marked mucosal edema. Helicobacter organisms occurred with equal frequency in both groups. The authors of that study concluded that the MFH cases represented Menetrier's disease but that the HLG cases represented a different entity that should not be labeled as Menetrier's disease (84).

Lymphocytic gastritis is frequently encountered in patients with $H$. pylori infection (87-89) and in adult and pediatric patients with celiac disease (87, 90-95). Between 10 and $45 \%$ of celiac patients have lymphocytic gastritis $(90,92)$. Most of these patients have an endoscopically normal stomach and do not have lesions of varioliform gastritis or hypertrophic gastritis. A finding of lymphocytic gastritis should always prompt clinical consideration of occult celiac disease. In one large series of 103 patients with biopsy-confirmed lymphocytic gastritis, 39 (38\%) had celiac disease, 13 (29\%) had H. pylori infection, and the remainder had a variety of intestinal conditions (87; Table 4). Approximately $4-10 \%$ of patients with $H$. pylori infection also have lymphocytic gastritis $(87,88)$. However, unlike celiac disease-associated lymphocytic gastritis, these patients often have epithelial neutrophil infiltration as well as lymphocytic infiltration. Lymphocytic gastritis in patients with celiac disease is more likely to involve the antrum, whereas corpus-predominant lymphocytic gastritis is more likely to represent Helicobacter infection $(87,95)$. Lymphocytic gastritis due to $H$. pylori infection may resolve after elimination of the infection $(83,88,89)$.

TABLE 4. Etiologic Associations of Lymphocytic Gastritis

Celiac disease

H. pylori infection

Varioliform gastritis

Lymphocytic gastroenterocolitis

Crohn's disease

HIV infection

Lymphoma

Unknown
A major differential diagnosis of lymphocytic gastritis is low-grade marginal-zone B-cell lymphoma (MALT lymphoma). In most cases, there is no problem making the distinction. In MALT lymphoma, the lamina propria is expanded and contains a monotonous infiltrate of densely packed monocytoid cells that are larger than small lymphocytes. In some cases, however, the infiltrate is plasmacytoid in appearance. Intraepithelial lymphoid cells are a common finding in MALT lymphoma. When compared with lymphocytic gastritis, the lymphoma cells tend to occur within lymphoepithelial lesions containing three or more cells. In addition, there is often active gland destruction (Fig. 18), a feature not encountered in lymphocytic gastritis. Lymphoma also tends to be associated with formation of Dutcher bodies and infiltration of the muscularis mucosae by lymphoid cells. Lymphoid follicles, crypt abscess formation and epithelial atypia are not useful features for distinguishing lymphoma from gastritis $(96,97)$. Because most intraepithelial lymphocytes of lymphocytic gastritis are of T-cell origin and most lymphocytes of MALT lymphoma are of B-cell origin, it should be possible to distinguish these entities by simple immunostaining methods. It must be recognized, however, that very occasional primary gastric T-cell lymphomas may occur $(98,99)$. These have a variety of immunophenotypes. Primary gastric T-cell lymphoma has also been associated with $H$. pylori and regression of the tumor after treatment of the infection has been described (100).

\section{GASTRITIS AND DUODENITIS IN PATIENTS WITH INFLAMMATORY BOWEL DISEASE}

Patients with Crohn's disease rarely have gross clinical involvement of the upper gastrointestinal tract, including the stomach and proximal duodenum. Microscopic inflammation is, however, considerably more common and may be detected in between 8 and $75 \%$ of patients $(101,102)$. Some of the gastritis in these individuals can be attributed to H. pylori infection (10-33\%), but in approximately $50 \%$ of individuals, the inflammation is considered to be a direct involvement by Crohn's disease. In approximately $10 \%$ of cases, mucosal granulomas may be detected (102), although the yield will be greatest when large numbers of biopsies are taken. In the nongranuloma cases, focal acute inflammation with a background of normal mucosa (focally enhanced gastritis) is the lesion most commonly encountered (101-102; Table 5). The inflammation may be centered on foveolae, glands, or the lamina propria (Fig. 19). Neutrophils and chronic inflammatory cells may be present (Fig. 20). The lymphocytes are typically CD3 positive and the histiocytes, 


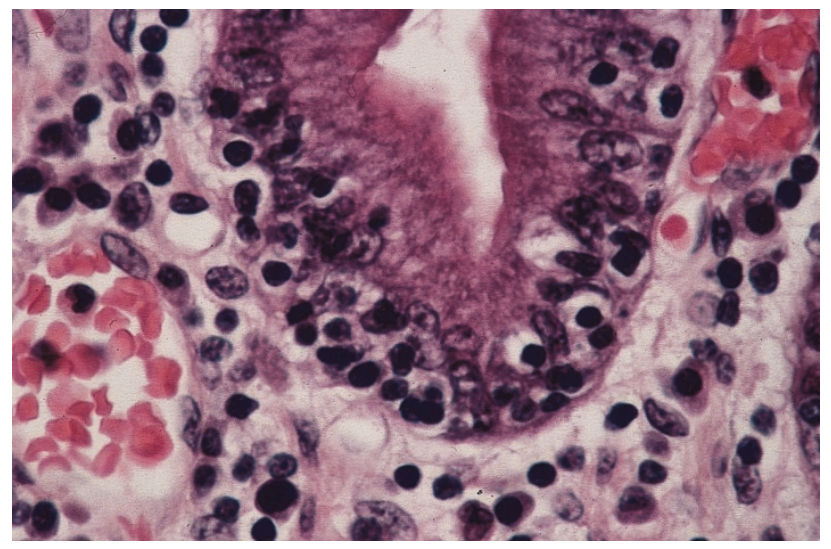

FIGURE 17. Intra-epithelial lymphocytes in lymphocytic gastritis. They are small and regular. No epithelial destruction is present.

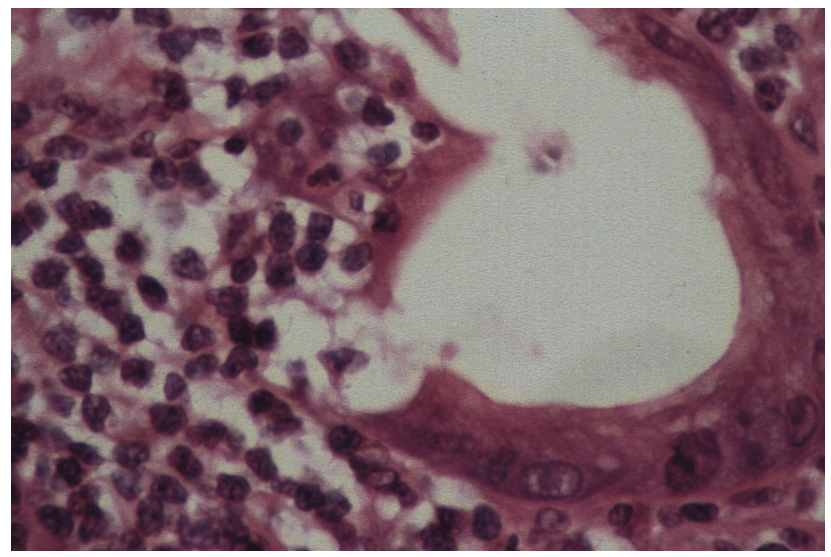

FIGURE 18. Lymphoepithelial lesion from a case of low-grade MALT lymphoma. Foveolar epithelial destruction is evident.

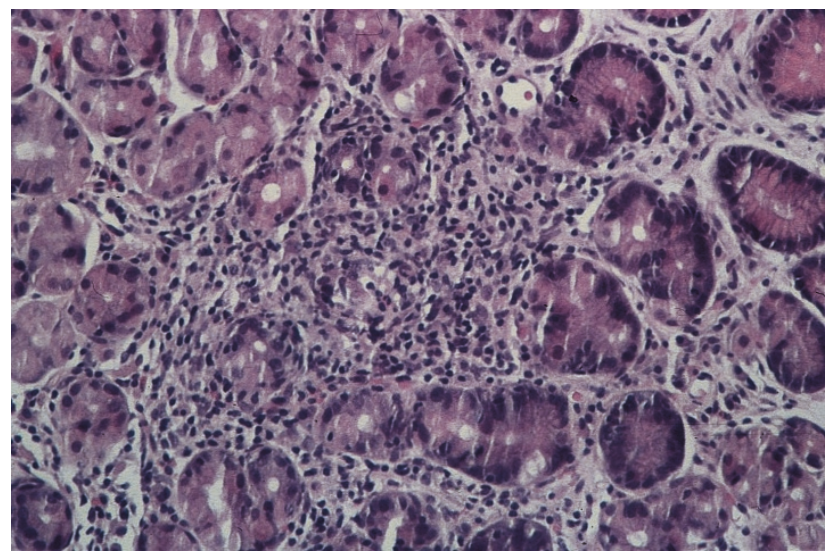

FIGURE 19. Crohn's disease of the stomach with focally enhanced gastritis (FEG). An isolated, partly destroyed gland is present, surrounded by a mixture of active and chronic inflammatory cells.

CD68R positive (101). Focally enhanced gastritis is more frequent in the antral mucosa $(48 \%)$ than in the corpus mucosa $(24 \%)$ of patients with upper intestinal Crohn's disease (101). Small numbers of patients with Crohn's disease may also have lymphocytic gastritis (102). In the duodenum, surface epithelial infiltration by neutrophils and deep acute

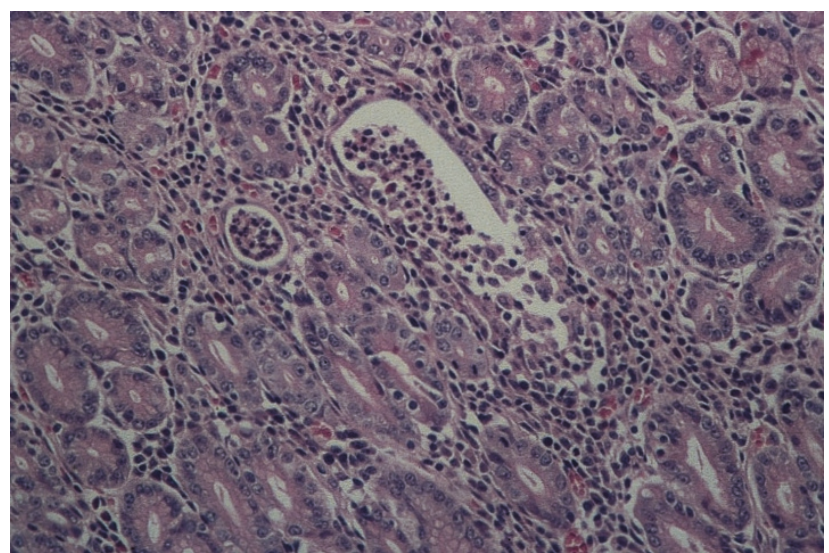

FIGURE 20. Focally enhanced gastritis with a pit abscess. Note that this lesion is surrounded by histologically normal mucosa.

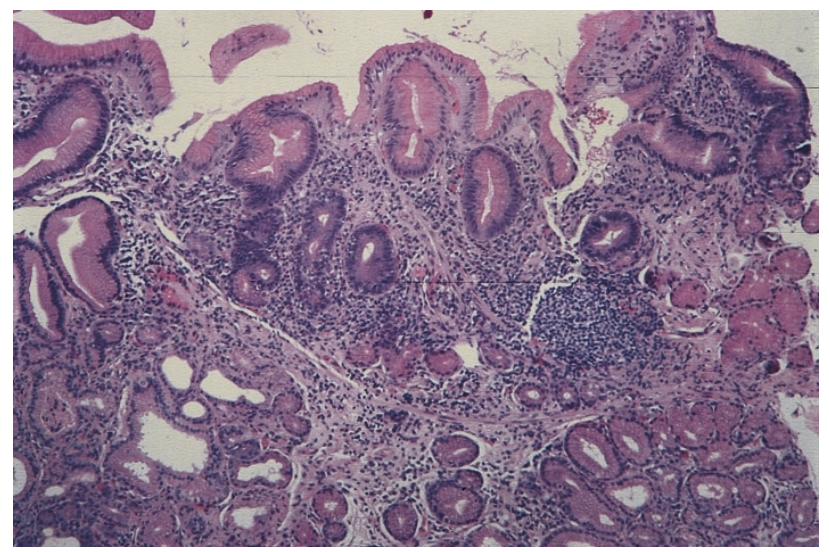

FIGURE 21. Carditis. Typically the inflammation is uneven and nonspecific in type.

inflammation may be encountered (102). Crohn's disease patients with histologic evidence of upper intestinal involvement have significantly more active small bowel disease than do those with negative findings (103). Focal gastritis and duodenitis have also been described in pediatric patients with Crohn's disease (104).

Rare examples of gastroduodenal inflammation have also been identified in patients with ulcerative colitis (104-107). The changes described have included multiple tiny shallow ulcers, crypt abscess formation, increased intraepithelial lymphocytes, and villous blunting. These changes vary in intensity and parallel remissions and relapses of colonic inflammation occurring in colonic mucosa (106). Perhaps the occurrence of duodenal inflammation is not so surprising when it is considered that ulcerative colitis is well known to be associated with both sclerosing cholangitis and sclerosing pancreatitis.

\section{EOSINOPHILIC GASTRITIS}

Small numbers of eosinophils are found commonly in a wide range of inflammatory diseases of 


\begin{tabular}{|c|c|c|c|c|}
\hline & Sensitivity & Specificity & $\begin{array}{c}\text { Negative Predictive } \\
\text { Value }\end{array}$ & $\begin{array}{c}\text { Positive Predictive } \\
\text { Value }\end{array}$ \\
\hline Focally enhanced gastritis & $31 \%$ & $98 \%$ & $53 \%$ & $95 \%$ \\
\hline Granuloma & $6 \%$ & $100 \%$ & $38 \%$ & $100 \%$ \\
\hline
\end{tabular}

the stomach. Eosinophilic gastritis should only be diagnosed when large numbers of eosinophils are present and particularly, when they occur as a sheetlike monomorphic population (108). In a few instances, eosinophilic gastritis is associated with a generalized connective tissue disorder such as scleroderma or polymyositis. In other instances, it may be secondary to infiltration of the wall of the stomach by parasitic larvae, for example anisakiasis, and constitutes a hazard of consuming improperly prepared sushi (109). In the majority of cases, however, eosinophilic gastritis is of unknown etiology. Peripheral blood eosinophilia is present in $\leq 75 \%$ of patients, and the disease often responds to corticosteroid therapy (108). The gastric antrum is the site most commonly involved, and the infiltration may be panmural or centred on the mucosa, muscularis propria, or serosal layers of the wall.

In children $<2$ years of age, allergies to cow's milk or soy protein may cause eosinophil infiltration of the gastric mucosa (110). The antrum is the main site of involvement. Marked infiltration is seen in most instances, but a minority of cases have only a patchy infiltration.

\section{GRANULOMATOUS GASTRITIS}

A wide variety of infectious and noninfectious diseases may give rise to gastric granulomas. In most examples of infectious granuloma formation, the cause is known, and granulomas are present in other tissues. Noninfectious granulomas may be secondary to Crohn's disease, sarcoidosis, or an adjacent gastric neoplasm (carcinoma or lymphoma) or may be idiopathic. A recent paper from the Cleveland Clinic (111) suggests that if patients are thoroughly investigated, the number of cases labeled as "idiopathic" is greatly reduced. Those investigators also found some cases of $H$. pylori gastritis characterized by formation of noncaseating granulomata.

\section{GASTRIC CARDIA-ANATOMIC DEFINITIONS}

By strict anatomic definition, the gastroesophageal junction is that point where the tubular esophagus becomes the saccular stomach. In practice, however, this definition is not very useful because intersection of these two organs is not sharp, and the junction may extend over a $5-10 \mathrm{~mm}$ segment. Commonly used landmarks of more practical value are the level of the peritoneal reflection on the serosal aspect of the stomach (if a surgical or autopsy specimen is available) or the most proximal limit of the gastric mucosal folds (if only endoscopic biopsy material is available). At least in children, these landmarks occur at the same site (112). The location of the Z-line (squamocolumnar junction) in children also coincides with the anatomic gastroesophageal junction and is regular in contour $(112,113)$. It can be seen therefore that, in biopsy material, knowledge of the precise location of the biopsy specimen is required for adequate microscopic interpretation. Pathologists are entirely dependent on endoscopists for this information.

\section{STATUS OF THE CARDIAC MUCOSA-DOES IT EXIST?}

The existence and status of the cardiac mucosa of the stomach is one of the more hotly debated topics in gastrointestinal pathology at the present time. There are two completely different opinions: one of which is that it is a normal finding; the second is that it presents a metaplastic response to reflux.

The term cardia of the stomach is loosely applied to a gross anatomical zone that extends for $10-20$ $\mathrm{mm}$ distal to the lower end of the esophagus. Cardiac mucosa is similar to pyloric mucosa, in which the glands occupy approximately $50 \%$ of the mucosal thickness and are mucous secreting. Cardiofundic mucosa is present where the glands contain a mixture of mucous-secreting and acid-secreting cells. According to the work of Kilgore et al. (112) and Zhou et al. (113), cardiac mucosa is invariably present distal to the gastroesophgeal junction in fetuses, infants, young children, and adolescents. The zone of pure cardiac mucosa in their studies was $1.0-4.0 \mathrm{~mm}$ in length (average, $1.8 \mathrm{~mm} ; 112$ ). In $37 \%$ of cases there was an abrupt transition between cardiac and fundic mucosa. In $40 \%$ of cases, an intervening zone of cardiofundic mucosa was also present that measured $<1 \mathrm{~mm}$ in length, and in $13 \%$ of cases, a zone of cardiofundic mucosa was present that measured $>1 \mathrm{~mm}$ in length. Cardiofundic mucosa, where present, occurred in addition to the zone of pure cardiac mucosa. Both sets of investigators have concluded that cardiac mucosa with or without an additional zone of cardiofundic mucosa is a normal finding in individuals under the age of 18 years. 
Ormsby et al. (114) examined the gastroesophageal junction in 223 unselected adult and pediatric autopsies. Again, the entire mucosal junction was histologically sectioned. Results remarkably similar to those of the previous studies' cases were obtained. In all cases, the proximal extent of the gastric mucosal folds coincided with the peritoneal reflection. Eighteen cases (8\%) had proximal extension of columnar mucosa into the esophagus, but in only 2 of these $(0.89 \%$ of the total population) was intestinal metaplasia (i.e., Barrett's esophagus) identified. Examination of the cardiac mucosa in these 223 cases revealed that metaplasia was present in 23 cases (10.3\%). However, in only 1 of these 23 cases of cardiac intestinal metaplasia was there coincidental proximal extension of columnar mucosa into the esophagus. There was, however, a strong association among cardiac intestinal metaplasia, chronic gastritis, and distal gastric intestinal metaplasia.

The concept of the normality of cardiac mucosa has been challenged by Chandrosoma and associates $(115,116)$. They studied the gastroesophageal junction region in unselected adult autopsies and found that when one section was taken through this region, $29 \%$ of cases had no cardiac or cardiofundic mucosa, $44 \%$ of cases had cardiofundic mucosa only, and only $29 \%$ of cases had a zone of pure cardiac mucosa. When the entire gastroesophgeal junction of a selected group of adult patients was studied, cardiofundic mucosa was present in all cases, but pure cardiac mucosa was present in only $44 \%$. Furthermore, they found that in many cases, the zone of cardiac and cardiofundic mucosa was incomplete and that in some sections, esophageal squamous epithelium was present immediately adjacent to pure fundic mucosa. In common with the findings of Kilgore et al. (112) and Zhou et al. (113), the zones of pure cardiac and cardiofundic mucosa were short, usually $<0.5 \mathrm{~cm}$ in length and never $>1.5 \mathrm{~cm}$. Chandrosoma et al. (115) also noted that when pure cardiac mucosa and cardiofundic mucosa were present, they were invariably inflamed to a greater or lesser degree. These findings have led to the suggestion that cardiac mucosa is not derived from the stomach but represents a metaplastic response of lower esophageal squamous epithelium to inflammation, particularly reflux.

\section{CAUSATION OF CARDITIS}

In starting this discussion, it is not necessary to decide whether cardiac mucosa is "normal" at the GE junction or represents an acquired metaplasia of the lower end of the esophagus. All observers recognize that this mucosa exists, may become inflamed, and may give rise to an increasing incidence of gastric cardiac cancer.
Two basic theories of causation exist: reflux disease and Helicobacter infection. Both are established as causes of cancer: H. pylori is a cause of distal gastric cancer, and reflux is a cause of adenocarcinoma of the distal esophagus. All investigators have used the term carditis to describe inflammation in cardiac mucosa rather than the cardia as a general anatomical region (Fig. 21). It should be noted, however, that there is no proof that cardiac cancer arises from cardiac mucosa. It could equally well arise from adjacent fundic-type mucosa located in the gross anatomical region of the cardia.

Carditis is a common finding in biopsy material, being present in between $75 \%$ and $95 \%$ of unselected patients undergoing endoscopy (117-119). Its incidence is the same in men and women (118, $119)$ but increases with age $(119,120)$. Intestinal metaplasia of the cardiac mucosa has been found in $10-22 \%$ of unselected patients $(114,120-122)$.

There is a strong association involving carditis, Helicobacter infection, and gastritis in the remainder of the stomach (123). In situations where infection is present, the intensity of carditis parallels that of antritis (122). Active carditis is present in $89 \%$ of patients in whom $H$. pylori is present in the stomach (124). Furthermore, in low-grade carditis, the $H$. pylori detection rate is only $12 \%$; however, in severe carditis, this figure rises to $57 \%$ (119). There is also a strong association between cardiac intestinal metaplasia and multifocal atrophic gastritis in the remainder of the stomach $(114,120)$. However, intestinal metaplasia is more likely to be found in columnar mucosa located at the squamocolumnar junction than it is in gastric mucosa $1-2 \mathrm{~cm}$ distal to this site (124). The last powerful piece of evidence linking $H$. pylori with carditis is the reduction or elimination of inflammation after antibiotic treatment $(125,126)$.

There is, however, also a significant association between carditis and GERD. Its prevalence in patients with GERD has been estimated variously to be between 34 and $100 \%$ (117, 122, 127-129). In contrast to $H$. pylori-associated carditis, GERD carditis is not associated with inflammation elsewhere in the stomach (121). Intestinal metaplasia of the cardia is detected in between 3 and $10 \%$ of patients with GERD $(118,122)$, being present in patients with clinical symptoms of GERD, but without $H$. pylori infection. Furthermore, there is a close correlation between the severity of GERD, as measured by 24-hour $\mathrm{pH}$ monitoring and the intensity of carditis (128). Patients with carditis secondary to GERD are likely to have fewer neutrophils in the epithelium than those individuals with carditis secondary to H. pylori (50\% with GERD versus $89 \%$ with $H$. pylori; 127). Large-scale epidemiologic studies have suggested a strong relationship between esophageal adenocarcinoma and GERD, but 
only a weak relationship between cardiac cancer and GERD (130).

From information available at the present time, it may be concluded that cardiac mucosa is probably a normal finding, although its extent is less than was previously supposed. This does not exclude the possibility that the zone of cardiac mucosa may expand after a period of gastroesophageal reflux. In a proportion of individuals, the cardiac-fundic mucosal interface comprises glands with a mixed cell population. Carditis has at least two causes: an isolated carditis associated with reflux and a pangastritis associated with $H$. pylori $(118,127,129)$. Further work on the gastric cardia would greatly benefit from use of standardized nomenclature, with strict attention paid to the exact site of the endoscopic biopsy in relation to anatomical landmarks (131).

\section{REFERENCES}

1. Talley NJ, Hunt RH. What role does Helicobacter pylori play in dyspepsia and non-ulcer dyspepsia? Arguments for and against $H$. pylori being associated with dyspeptic symptoms. Gastroenterology 1997;113(6 Suppl):S67-77.

2. Warren JR. Gastric pathology associated with Helicobacter pylori. Gastroenterol Clin North Am 2000;29:705-51.

3. Talley NJ, Janssens J, Lauritsen K. Eradication of Helicobacter pylori in functional dyspepsia: randomized double blind placebo controlled trial with 12 months' follow up. Br Med J 1999;318:833-57.

4. Elta GH, Appelman HD, Behier EM, et al. A study of the correlation between endoscopic and histologic diagnosis in gastroduodenitis. Am J Gastroenterol 1987;82:749-53.

5. Gad A. Erosion: a correlative endoscopic histological multicentric study. Endoscopy 1986;18:76-9.

6. Appelman H. Gastritis: terminology, etiology and clinicopathological correlations: another biased view. Hum Pathol 1994;25:1006-19.

7. Khakoo SI, Lobo AJ, Shepherd NA, Wilkinson SP. Histological assessment of the Sydney classification of endoscopic gastritis. Gut 1994;35:1172-5.

8. Carpenter HA, Talley NJ. Gastroscopy is incomplete without biopsy: clinical relevance of distinguishing gastropathy from gastritis. Gastroenterology 1995;108:917-24.

9. Dixon MF, Genta RM, Yardley JH, Correa P. Classification and grading of gastritis: the updated Sydney system. Am J Surg Pathol 1996;20:1161-81.

10. Whitehead R. The classification of chronic gastritis: current status. J Clin Gastroenterol 1995;21(Suppl 1):S131-4.

11. Blaser MJ. Hypothesis on the pathogenesis and natural history of Helicobacter pylori-induced inflammation. Gastroenterology 1992;102:720-7.

12. Kuipers EJ, Klinkenberg-Knol EC, Vandenbroucke-Grauls CM, et al. Role of Helicobacter pylori in the pathogenesis of atrophic gastritis. Scand J Gastroenterol Suppl 1997;223:2834.

13. Genta RM. Helicobacter pylori, inflammation, mucosal damage and apoptosis: pathogenesis and definition of gastric atrophy. Gastroenterology 1997;113(6 Suppl):S51-5.

14. Robert ME, Weinstein WM. Helicobacter pylori associated gastric pathology. Gastroenterol Clin North Am 1993;22:5972 .
15. Ruiz B, Garay J, Johnson E, et al. Morphometric assessment of gastric antral atrophy: comparison with visual evaluation. Histopathology 2001;39:235-42.

16. Correa P. Helicobacter pylori and gastric carcinogenesis. Am J Surg Pathol 1995;19(Suppl 1):S37-43.

17. Vemura N, Okamoto S, Yamamoto S, et al. Helicobacter pylori infection and the development of gastric cancer. N Engl J Med 2001;345:784-9.

18. Kuipers EJ, Lundell L, Klinkenberg-Knol EC, et al. Atrophic gastritis and Helicobacter pylori infection in patients with reflux esophagitis treated with omeprazole or fundoplication. N Engl J Med 1996;334:1018-22.

19. Satob K. Does eradication of Helicobacter pylori reverse atrophic gastritis or intestinal metaplasia? Data from Japan. Gastroenterol Clin North Am 2000;29:829-35.

20. Genta RM. Atrophy, acid suppression and Helicobacter pylori infection: a tale of two studies. Eur J Gastroenterol Hepatol 1999;1:529-33.

21. Fiocca R, Luinetti O, Villani L, et al. Epithelial cytotoxicity, immune responses and inflammatory components of $\mathrm{Hel}$ icobacter pylori gastritis. Scand J Gastroenterol 1994; 205(Suppl):11-21.

22. Ernst PB, Crowe SE, Reyes VE. How does Helicobacter pylori cause mucosal damage? The inflammatory response. Gastroenterology 1997;113(Suppl 6):S35-42.

23. Recentlon gastric mucosal damage, gastric cancer and MALT lymphoma. Gastroenterology 1997;113(Suppl 6):S65-6.

24. Axon AT. Are all helicobacters equal? Mechanisms of gastroduodenal pathology and their clinical implications. Gut 1999;45(Suppl):1-4.

25. Nogueira C, Figueiedo C, Carneiro F, et al. Helicobacter pylori genotypes may determine gastric histopathology. Am J Pathol 2001;158:647-54.

26. Valle J, Kekki M, Sipponen, Ihamaki T, Siurala M. Long term course and consequences of Helicobacter pylori gastritis. Results of a 32-year follow-up study. Scand J Gastroenterol 1996;31:546-550.

27. Solcia E, Fiocca R, Villani L, Luinetti O, Capella C. Hyperplastic, dysplastic and neoplastic enterochromaffin-like cell proliferations of the gastric mucosa. Am J Surg Pathol 1995; 19(Suppl):SI-7.

28. Kokkola A, Sjoblom SM, Haapiainen R, et al. The risk of gastric carcinoma and carcinoid tumors in patients with pernicious anemia. A prospective follow-up study. Scand J Gastroenterol 1998;33:88-92.

29. Ban-Hock T, van Driel IR, Gleeson PA. Pernicious anemia. N Engl J Med 1997;337:1441-8.

30. Negrini R, Savio A, Appelmelk BJ. Autoantibodies to gastric mucosa in Helicobacter pylori infection. Helicobacter 1997; 2(Suppl 1):S13-6.

31. Faller G, Winter M, Steininger H, et al. Gastric autoantibodies and gastric secretary function in Helicobacter pyloriinfected patients with duodenal ulcer and non-ulcerdyspepsia. Scand J Gastroenterol 1998;33:276-82.

32. Faller G, Steininger H, Kranziein J, et al. Antigastric autoantibodies in Helicobacter pylori infection: implications of histological and clinical parameters of gastritis. Gut 1997; 41:619-23.

33. Faller G, Kirchner T. Role of gastric autoantibodies in chronic Helicobacter pylori infection. Microsc Res Tech 2000;15:321-6.

34. Claeys D, Faller G, Appelmelk BJ, Negrini R, Kirchner T. The gastric $\mathrm{H}+\mathrm{K}+$ ATPase is a major autoantigen in chronic Helicobacter pylori gastritis with body mucosal atrophy. Gastroenterology 1998;115:340-7.

35. Stopeck A. Links between Helicobacter pylori infection, cobalamin deficiency and pernicious anemia. Arch Intern Med 2000;160:1229-30. 
36. Kaptan K, Beyan C, Ural AU, et al. Helicobacter pylori-is it a novel causative agent of vitamin BI2 deficiency? Arch Intern Med 2000;160:1349-53.

37. Varis O, Valle J, Siurala M. Is Helicobacter pylori involved in the pathogenesis of the gastritis characteristic of pernicious anemia? Scand J Gastroenterol 1993;28:705-8.

38. Tepes B, Kavcic B, Zaletel LK, et al. Two-to-four-year histological follow-up of gastric mucosa after Helicobacter pylori eradication. J Pathol 1999;188:24-9.

39. Ohkusa T, Fujiki K, Takashimizu I, et al. Improvement in atrophic gastritis and intestinal metaplasia in patients in whom Helicobacter pylori was eradicated. Ann Intern Med 2001;134:380-6.

40. Valle J, Seppala K, Sipponen P, Kosunen T. Disappearance of gastritis after eradication of Helicobacter pylori. A morphometric study. Scand J Gastroenterol 1991;26:1057-65.

41. Genta RM, Lew GM, Graham DY. Changes in the gastric mucosa following eradication of Helicobacter pylori. Mod Pathol 1993;6:281-9.

42. Sung JJ, Lin SR, Ching JY, et al. Atrophy and intestinal metaplasia one year after cure of $H$. pylori infection: a prospective, randomised study. Gastroenterology 2000;119: $7-14$.

43. Forbes GM, Warren JR, Glaser ME, et al. Long-term follow-up of gastric histology after Helicobacter pylori eradication. J Gastroenterol Hepatol 1996;11:670-3.

44. Kuipers EJ, Uyterlinde AM, Pena AS, et al. Increase of Helicobacter pylori associated corpus gastritis during acid suppressive therapy: implications for long-term safety. Am J Gastroenterol 1995;90:1401-6.

45. Moayyedi $\mathrm{P}$, Watson $\mathrm{P}$, Peacock R, et al. Changing patterns of Helicobacter pylori gastritis in long standing acid suppression. Helicobacter 2000;5:206-14.

46. Klinkenberg-Knol EC, Nelis F, Dent J, et al. Long-term omeprazole treatment in resistant gastroesophageal reflux disease: efficacy, safety and influence on gastric mucosa. Gastroenterology 2000;118:661-9.

47. Lundell L, Miettinen P, Myrvold HE, et al. Lack of effect of acid suppression on gastric atrophy. Gastroenterology 1999;117:319-26.

48. Driman DK, Wright C, Tongas G, et al. Omeprazole produces parietal cell hypertrophy and hyperplasia in humans. Dig Dis Sci 1996;41:2039-47.

49. Chondhry U, Boyce HW Jr, Coppola D. Proton pump inhibitor-associated gastric polyps. Am J Clin Pathol 1998; 110:615-21.

50. Cats A, Schenk BE, Bloemena E, et al. Parietal cell protrusions and fundic gland cysts during omeprazole maintenance treatment. Hum Pathol 2000;31:684-90.

51. Krishnamurthy S, Dayal Y. Parietal cell protrusions in gastric ulcer disease. Hum Pathol 1997;28:1126-30.

52. Aprile MR, Azzoni C, Gibril F, Jensen RT, Bordi C. Intramucosal cysts in the body of patients with Zollinger-Ellison syndrome. Hum Pathol 2000;31:140-8.

53. Vieth M, Stolte M. Fundic gland polyps are not induced by proton pump inhibitor therapy. Am J Clin Pathol 2001;116: 716-20.

54. McNulty CA, Dent JC, Curry A, et al. New spiral bacterium in gastric mucosa. J Clin Pathol 1989;42:585-91.

55. Oliva MM, Lazenby AJ, Perman JA. Gastritis associated with Gastrospirillum hominis in children. Comparison with Helicobacter pylori and review of the literature. Mod Pathol 1993;6:513-5.

56. Hilzenrat N, Lamoureux E, Weintraub I, et al. Helicobacter heilmannii-like spiral bacteria in gastric mucosal biopsies. Prevalence and clinical significance. Arch Pathol Lab Med 1995;119:1149-53.

57. Holck S, Ingeholm P, Blom J, et al. The histopathology of human gastric mucosa inhabited by Helicobacter heilmannii-like (Gastrospirillum hominis) organisms, including the first culturable case. APMIS 1997;105:746-56.

58. Svec A, Kordas P, Paviis Z, Novotny J. High prevalence of Helicobacter heilmannii-associated gastritis in a small predominately rural area: further evidence in support of a zoonosis? Scand J Gastroenterol 2000;35:925-8.

59. Yali Z, Yamada N, Won M, Matsuhisa T, Miki M. Gastrospirillum hominis and Helicobacter pylori infection in Thai individuals - comparison of histopathological changes of gastric mucosa. Pathol Int 1998;48:507-11.

60. Mazzucchelli L, Wilder-Smith CH, Ruchti C, Meyer-Wyss B, Merki HS. Gastrospirillum hominis in asymptomatic healthy individuals. Dig Dis Sci 1993;38:2087-9.

61. Meining A, Krohler G, Stolte M. Animal reservoirs in the transmission of Helicobacter heilmannii. Scand J Gastroenterol 1998;33:795-8.

62. Dixon MF, O'Connor HJ, Axon ATR, King RFJG, Johnson D. Reflux gastritis: distinct histopathology entity. J Clin Pathol 1986;39:524-30.

63. Ritchie WP Jr. Alkaline reflux gastritis. Gastroenterol Clin North Am 1994;23:281-94.

64. Burden WR, Hodges RP, Hsu M, O'Leary JP. Alkaline reflux gastritis. Surg Clin North Am 1991;71:33-44.

65. Sobala GM, King RFG, Axon ATR, Dixon MF. Reflux gastritis in the intact stomach. J Clin Pathol 1990;43:303-6.

66. Wilson P, Jamieson JR, Hindier RA, et al. Pathologic duodenogastric reflux associated with persistence of symptoms after cholecystectomy. Surgery 1995;117:421-8.

67. Haber MM, Lopez I. Reflux gastritis in gastroesophageal reflux disease: a histopathological study. Ann Diagn Pathol 1999;3:281-6.

68. Dixon MF, Neville PM, Mapstone NP, Moayyedi P, Axon AT. Bile reflux gastritis and Barrett's esophagus: further evidence of a role for duodenogastric-oesophageal reflux. Gut 2001;49:359-63.

69. McCarthy DM. Helicobacter pylori infection and gastroduodenal injury by non-steroidal anti-inflammatory agents. Scand J Gastroenterol Suppl 1991;187:91-7.

70. McCarthy CJ, McDermott M, Hourihane D, O’Morain C. Chemical gastritis induced by naproxen in the absence of Helicobacter pylori infection. J Clin Pathol 1995;48:61-3.

71. Quinn CM, Bjarnason I, Price AB. Gastritis in patients on non-steroidal anti- inflammatory drugs. Histopathology 1993;23:341-8.

72. Laine L. Non-steroidal anti-inflammatory drug gastropathy. Gastrointest Endosc Clin N Am 1996;6:489-504.

73. Voutilainen M, Sokka T, Juhola M, Farkkila M, Hannonen P. Non-steroidal anti-inflammatory drug-associated upper gastrointestinal lesions in rheumatoid arthritis patients. Relationships to gastric histology, Helicobacter pylori infection and other risk factors for peptic ulcer. Scand J Gastroenterol 1998;33:811-6.

74. Haber MM, Lopez L. Gastric histologic findings in patients with non-steroidal anti-inflammatory drug-associated gastric ulcer. Mod Pathol 1999;12:592-8.

75. Frezza AA, Gorji N, Molato M. The histopathology of nonsteroidal anti- inflammatory drug induced gastroduodenal damage: correlation with Helicobacter pylori, ulcers, and hemorrhagic events. J Clin Pathol 2001;54:521-5.

76. FitzGerald GA, Patrono C. The coxibs, selective inhibitors of cyclooxygenase-2. N Engl J Med 2001;345:433-42.

77. El-Zimaity HM, Genta RM, Graham DY. Histological features do not define NSAID-induced gastropathy. Hum Pathol 1996;27:1348-54.

78. Dixon MF, O'Connor HJ, Axon AT, King RF, Johnston D. Reflux gastritis: distinct histopathological entity? J Clin Pathol 1986;39:524-30. 
79. Haot J, Hamichi L, Waliez L, Mainguet P. Lymphocytic gastritis: a newly described entity: a retrospective endoscopic and histological study. Gut 1988;29:1258-64.

80. Haot J, Jouret A, Willette M, Gossuin A, Mainguet P. Lymphocytic gastritis-prospective study of its relationship with varioliform gastritis. Gut 1990;31:282-5.

81. Haot J, Bogomoletz WY, Jouret A, Mainguet P. Menetrier's disease with lymphocytic gastritis: an unusual association with possible pathogenetic implications. Hum Pathol 1991; 22:379-86.

82. Wolber RA, Owen DA, Anderson FH, Freeman HJ. Lymphocytic gastritis and giant folds associated with gastrointestinal protein loss. Mod Pathol 1991;4:13-5.

83. Groisman GM, George J, Berman D, Harpaz N. Resolution of protein-losing hypertrophic lymphocytic gastritis with therapeutic eradication of Helicobacter pylori. Am J Gastroenterol 1994;89:1548-51.

84. Wolfsen HC, Carpenter HA, Talley NJ. Menetrier's disease: a form of hypertrophic gastropathy or gastritis? Gastroenterology 1994;106:1310-9.

85. Dixon MF, Wyatt JL, Burke DA, Rathbone BJ. Lymphocytic gastritis-relationship to Campylobacter pylori infection. J Pathol 1988;154:125-32.

86. Jaskiewicz K, Price SK, Zak J, Louwrens HD. Lymphocytic gastritis in non-ulcer dyspepsia. Dig Dis Sci 1991;36:107983.

87. Wu TT, Hamilton SR. Lymphocytic gastritis: association with etiology and topology. Am J Surg Pathol 1999;23:153-8.

88. Niemela S, Karttunen T, Kerola T, Karttunen R. Ten year follow-up study of lymphocytic gastritis: further evidence on Helicobacter pylori as a cause of lymphocytic gastritis and corpus gastritis. J Clin Pathol 1995;48:1111-6.

89. Hayat M, Arora DS, Dixon MF, Clark B, O’Mahony S. Effects of Helicobacter pylori eradication on the natural history of lymphocytic gastritis. Gut 1999;45:495-8.

90. Wolber RA, Owen D, DelBuono L, Appelman H, Freeman HJ. Lymphocytic gastritis in patients with celiac sprue or sprue like intestinal disease. Gastroenterology 1990;21:1092-6.

91. Jevon GP, Dimmick JE, Dohil R, Hassall EG. Spectrum of gastritis in celiac disease in childhood. Pediatr Dev Pathol 1999;2:221-6.

92. Feeley KM, Heneghan MA, Stephens FM, McCarthy CF. Lymphocytic gastritis and coeliac disease: a positive association. J Clin Pathol 1998;51:207-10.

93. Lynch DA, Sobala GM, Dixon MF, et al. Lymphocytic gastritis and associated small bowel disease: a diffuse lymphocytic gastroenteropathy. J Clin Pathol 1995;48:939-45.

94. Alsaigh N, Odze R, Goldman H, et al. Gastric and esophageal intraepithelial lymphocytes in pediatric celiac disease. Am J Surg Pathol 1996;20:865-70.

95. Hayat M, Arora DS, Wyatt JI, O'Mahony S, Dixon MF. The pattern of involvement of the gastric mucosa in lymphocytic gastritis is predictive of the presence of duodenal pathology. J Clin Pathol 1999;52:815-9.

96. Zukerberg LR, Ferry JA, Southern JF, Harris NL. Lymphoid infiltrates of the stomach. Evaluation of histologic criteria for the diagnosis of low-grade gastric lymphoma on endoscopic biopsy specimens. Am J Surg Pathol 1991;15:1014-6.

97. Isaacson PG. Recent developments in our understanding of gastric lymphoma. Am J Surg Pathol 1996;20(Suppl 1):51-7.

98. Foss HD, Schmitt-Graff A, Daum S, et al. Origin of primary gastric T-cell lymphoma from intraepithelial T lymphocytes: report of two cases. Histopathology 1999;34:9-15.

99. Barth TF, Leithauser F, Dohner $\mathrm{H}$, et al. Primary gastric apoptosis-rich T-cell lymphoma co-expressing CD4, CDS and cytotoxic molecules. Virchows Arch 2000;436:357-64.

100. Bariol C, Field A, Vickers CR, Ward R. Regression of gastric $\mathrm{T}$ cell lymphoma with eradication of Helicobacter pylori. Gut 2001;42:269-71.
101. Oberhuber G, Puspok A, Oesterroicher C, et al. Focally enhanced gastritis-a frequent type of gastritis in patients with Crohn's disease. Gastroenterology 1997;112:698-706.

102. Wright CL, Riddell RH. Histology of the stomach and duodenum in Crohn's disease. Am J Surg Pathol 1998;22:38390.

103. Halme L, Karkkainen P, Rautelin H, Kosunen TU, Sipponen P. High frequency of helicobacter negative gastritis in patients with Crohn's disease. Gut 1996;38:379-83.

104. Tobin JM, Sinha B, Ramani P, Saleh AR, Murphy MS. Upper gastrointestinal mucosal disease in pediatric Crohn disease and ulcerative colitis. A blinded control study. J Pediatr Gastroenterol Nutr 2001;32:443-8.

105. Sasaki M, Okada K, Kayama S, et al. Ulcerative colitis complicated by gastroduodenal lesions. J Gastroenterol 1996; 31:585-9.

106. Mitomi H, Atari E, Uesugi H, et al. Distinctive diffuse duodenitis associated with ulcerative colitis. Dig Dis Sci 1997; 42:684-93.

107. Terashima S, Hoshino Y, Kanzaki N, Kogure M, Gotoh M. Ulcerative duodenitis accompanying ulcerative colitis. J Clin Gastroenterol 2001;32:172-5.

108. Johnstone JM, Morson BC. Eosinophilic gastro-enteritis. Histopathology 1978;2:349-61.

109. Pincus GS, Coolidge C, Little MD. Intestinal anisakiasis. First case report from North America. Am J Med 1975;59: 114-20.

110. Goldman H, Projansky R. Allergic proctitis and gastroenteritis in children. Clinical and mucosal biopsy features in 53 cases. Am J Surg Pathol 1986;10:75-86.

111. Shapiro JL, Goldblum JR, Petras RE. A clinicopathologic study of 42 patients with granulomatous gastritis. Is there really an "idiopathic" granulomatous gastritis? Am J Surg Pathol 1996;20:462-70.

112. Kilgore SP, Ormsby AH, Gramlich TL, et al. The gastric cardia: fact or fiction? Am J Gastroenterol 2000;95:921-4.

113. Zhou H, Greco MA, Daum F, Kahn E. Origin of cardiac mucosa: ontogenic considerations. Pediatr Dev Pathol 2001;4:358-63.

114. Ormsby AH, Kilgore SP, Goldblum JR, et al. The location and frequency of intestinal metaplasia at the esophagogastric junction in 223 consecutive autopsies: implications for patient treatment and preventative strategies in Barrett's esophagus. Mod Pathol 2000;13:614-20.

115. Chandrosoma PT, Der R, Ma Y, Dalton P, Taira M. Histology of the gastroesophageal junction: an autopsy study. Am J Surg Pathol 2000;24:40-409.

116. Chandrosoma PT. Letter to editor. Am J Gastroenterol 2000; 95:2384-5.

117. Morini S, Zullo A, Hassan C, et al. Gastric cardia inflammation: role of Helicobacter pylori infection and symptoms of gastroesophageal reflux disease. Am J Gastroenterol 2001; 96:2337-40.

118. Voutilainen M, Farkkila M, Mocklin JP, et al. Chronic inflammation at the gastroesophageal junction (carditis) appears to be a specific finding related to Helicobacter pylori infection and gastroesophageal reflux disease. Am J Gastroenterol 1999;94:3175-80.

119. Chen YY, Antonioli DA, Spechler SJ, et al. Gastroesophageal reflux disease versus Helicobacter pylori infection as the chief cause of carditis. Mod Pathol 1998;11:950-6.

120. Voutilainen M, Farkkila M, Juhola M, Mocklin JP, Sipponen P. Complete and incomplete intestinal metaplasia at the oesophagogastric junction: prevalence and associations with endoscopic erosive esophagitis and gastritis. Gut 1999; 45:644-8.

121. Polkowski W, van Lanschoft JJ, ten Kate FJ, et al. Intestinal and pancreatic metaplasia at the esoghagogastric junction 
in patients with Barrett's esophagus. Am J Gastroenterol 2000;95:617-25.

122. Goldblum JR, Vicari JJ, Falk GW, et al. Inflammation and intestinal metaplasia of the gastric cardia: the role of gastroesophageal reflux and H. pylori infection. Gastroenterology 1998;114:633-9.

123. Genta RM, Hiihorman RM, Graham DY. The gastric cardia in Helicobacter pylori infection. Hum Pathol 1994;25: 915-9.

124. Lembo T, Ippoliti AF, Ramers C, Weinstein WM. Inflammation of the gastro-esophageal junction (carditis) in patients with symptomatic gastro-esophageal reflux disease: a prospective study. Gut 1999;45:484-8.

125. el-Zimaity HM, Verghose UJ, Ramchatesingh J, Graham DY. The gastric cardia in gastro-esophageal disease. J Clin Pathol 2000;53:619-25.

126. Sharma P, Topalovski M, Mayo MS, Sampliner RE, Weston AP. Helicobacter pylori eradication dramatically improves inflammation in the gastric cardia. Am J Gastroenterol 2000;95:3107-11.

127. Bowery DJ, Clark GW, Williams GT. Patterns of gastritis in patients with gastro-oesophageal reflux disease. Gut 1999; 45:798-803.

128. Der R, Tsao-Wei DD, Demeester T, et al. Carditis: a manifestation of gastroesophageal reflux disease. Am J Surg Pathol 2001;25:245-52.

129. Goldstein NS, Karim R. Gastric cardia inflammation and intestinal metaplasia: association with reflux esophagitis and Helicobacter pylori. Mod Pathol 1999;12:101724.

130. Lagergren J, Bergstrom R, Lindgren A, Nyren O. Symptomatic gastroesophageal reflux as a risk factor for esophageal cancer. N Engl J Med 1999;340:825-31.

131. Spechler SJ. The role of gastric carditis in metaplasia and neoplasia at the gastroesophageal junction. Gastroenterology 1999;117:218-28.

\section{Book Review}

\section{Stockham SL, Scott MA: Fundamentals of Vet- erinary Clinical Pathology, 368 pp, Ames, IA, lowa State Press, A Blackwell Publish- ing Company, 2001 (\$74.99).}

This book, written primarily for the sophomore students of veterinary medicine, is a compendium of laboratory medicine cum pathophysiology. It is an important contribution to the teaching of laboratory medicine, and all medical laboratorians involved in education would be well advised to get a copy for their teaching files. In a somewhat abbreviated form, and by deleting the word veterinary from its title, it easily could be used in any medical school here and abroad.

The authors, who have been teaching clinical pathology for more than 20 years, apparently know not only which aspects of laboratory medicine are most important, but also know how to present them and how to tie and relate the new fact to the students' knowledge of other preclinical subjects. They also know how to make the topics clinically relevant. Clinical interpretation of the laboratory data is the major strength of the book. It contains numerous clinical scenarios that enliven the bare facts and numbers that often scare or repulse students from learning laboratory medicine. To show off that I have learned something important or interesting, let me give just two examples:

The major emphasis is on blood chemistry and hematology, but there are also chapters on the analysis of urine and endocrinology. I imagine that cerebrospinal fluid and other body fluids are rarely examined in animals, and transfusions are rarely performed, because these topics are mentioned only in passing. Hematology is illustrated in color plates. Excellent line drawings are used to illustrate the pathophysiologic basis of important concepts and laboratory abnormalities. Even a person like me, who pleads ignorance when it comes to veterinary medicine, could profit from this text. To show off that I have learned something, here are a few interesting tidbits: Hypophosphatemia from hyperalimentation of starved dogs can reduce the survival of platelets in circulation and lead to thrombocytopenia. Cows that drink too much water can have hypoosmotic hemolysis. Horses that eat rhubarb (high on oxalates!) can develop hypocalcemia.

The book is primarily intended for sophomore students, and as such it reads almost like a collection of very detailed lecture notes. I mean this as a compliment and to indicate that the book is ideally suited for a well-organized course in laboratory medicine. I wish only that the students at our Medical School had such a course! The practicing veterinarians also could read it to refresh their knowledge of the basics, but also as a sourcebook for interpreting laboratory findings.

\section{Ivan Damjanov \\ University of Kansas School of Medicine Kansas City, Kansas}

